\title{
THE CONTENT OF LANDSCAPE FORM [THE LIMITS OF FORMALISM]
}

\author{
Marc Treib
}

Marc Treib is Professor of Architecture at the University of California at Berkeley, a practicing designer, and a frequent contributor to architecture, landscape and design journals. He has held Fulbright, Guggenheim, and Japan Foundation fellowships, as well as an advanced design fellowship at the American Academy in Rome. Professor Treib is the author of Sanctuaries of Spanish New Mexico (University of California Press, 1993), editor of Modern Landscape Architecture: A Critical Review (MIT Press, 1993) and co-author of A Guide to the Gardens of Kyoto (Shufunotomo, 1980). The Regional Garden in the United States, which he co-edited, was published in 1996, as was Space Calculated in Seconds: The Philips Pavilion, Le Corbusier and Edgar Varèse (Princeton University Press). Forthcoming in 2002 are The Architecture of Landscape, 1940-60 (University of Pennsylvania Press) and Thomas Church, Landscape Architect (Monacelli Press).
Abstract: The values behind the question of landscape appreciation and evaluation also inform the greater question of landscape content. Here the content of landscape architecture is taken as the raw material transformed through design, material from which we may derive pleasure and/or significance. What sort of raw material, its potential and its relevance, is the essay's subject. Admittedly, structure, space, and pattern may constitute content in and of themselves, a poetics of form and space. But deeper works may result from using these vehicles to embody other types of content, among them the understanding and judicious application of ecological processes (including the immediate as well as larger site over time), and the regard for humans singly and in groups, contemporary and over time. The manner in which the designer addresses these factors may also elevate a physical statement of these concerns, alone or together, to a poetic level. It is admittedly a difficult task, and without doubt, no work is ever perfect in all respects. Nonetheless, several landscape architects currently in practice have produced designs with these considerations at their core. The work of Hargreaves Associates in the United States, and Georges Descombes and Dieter Kienast in Switzerland serve as the prime case studies.

The landscape architect's project here utilizes the eternalized moment of history to inform the making of physical places. The landscape must succeed in the present-social provisions, construction intelligence, aesthetic interest_amalgamating the voices of the past with those of the "now."
$\mathrm{H}$ ow do we evaluate and appreciate landscape architecture? Is it the skill with which the walls, rills, and floors have been designed and crafted, the power of the spaces, the formal beauty alone? Or do we praise the success with which the spaces please us, how they provide warmth in a cold climate, a sweet fragrance among dust, or places for sitting and human conduct, or settings to eat or to dream? Do we appreciate a design because it seems so appropriate to the climate or to the topography, or as an escape from it? Do we reward the landscape architect for using a minuscule amount of water in a desert landscape, no matter the corollary sensual deprivation?

The question of appreciation and evaluation informs the greater question of landscape content. Of what value is a landscape design; what is its content? It has been said that since there is no landscape without content, so can there be no work of landscape architecture without content. This assumption has particular resonance if one believes, as I do, that meaning derives from the transaction between the perceiver and the artifact. ${ }^{1}$ According to this way of thinking the designed landscape serves essentially as the material for sense and interpretation. Ultimate comprehension and pleasure rest with the individual influenced, perhaps formed, by his or her cultural matrix. Of course, other schools of thought do exist, and several of them hold that it is possible to imbue meaning in the course of design and making, especially in cultures bound within a common system of belief. In this essay, I would request a temporary suspension of disbelief from those who follow this latter view. Here I would propose that the content of landscape design is the raw material to be transformed through design, material from which we may derive pleasure and/or significance. What sort of raw material, its potential and its relevance, is the basis of the essay's subject. Of the panoply of possible sources of content, for reasons hopefully explained below, I will focus on ecology, social/historical aspects, and form (and space) themselves. 


\section{Form/Formalism}

In recent years, that is at least since the mid-1980s, landscapes structured by patterning, realized in natural and synthetic materials, and restricted in vegetation have received considerable attention and widespread publication. For the most part these designs strike vivid retinal images and make striking photographs; they are experienced on site as exercises in order and form. They may be beautiful or ungainly, pure or assembled, uniquely crafted or drawn from varied vernacular and industrial elements (Figure 1). While their visual interest is, for the most part, undeniable, often their experience as landscape-considering the full potential offered by a designed landscape-is circumscribed and limited. What works in the photograph does not Eecessarily thrill on site or maintain continued interest over time. Is this Fifecause the work itself lacks suffiEient richness, or that the photoĝ.raph (through isolation, recompositron, idealized lighting condition, Etc.) has so increased the power of thige place that it is difficult to match this image on site? ${ }^{2}$

Since its invention in the ninetêtenth century, the photographic imgige, as printed or more recently digi它zed, has exerted a potent influence uppon the formulation and witnessing of the designed landscape. ${ }^{3}$ Of סूourse, photographic experience is, Бुy its very nature, more narrowly limed to the visual sense, in turn, suppّressing the haptic, olfactory, audiTory, and temporal dimensions of andscape perception. The resultsadly, to my mind-reduces the potentially manifold dimensions of experience to only two. In the process, the formal aspects become the purpose or content of the design; the image reigns supreme. ${ }^{4}$

While the skill of design, construction, and detail certainly constitute a subject in and of themselves, there are limits to the continued effect of this formalism and the attitude with which it regards the environment and society. Form as content is an old story in modern painting, of course, and to a lesser extent in architecture. Critic Clement Greenberg argued that

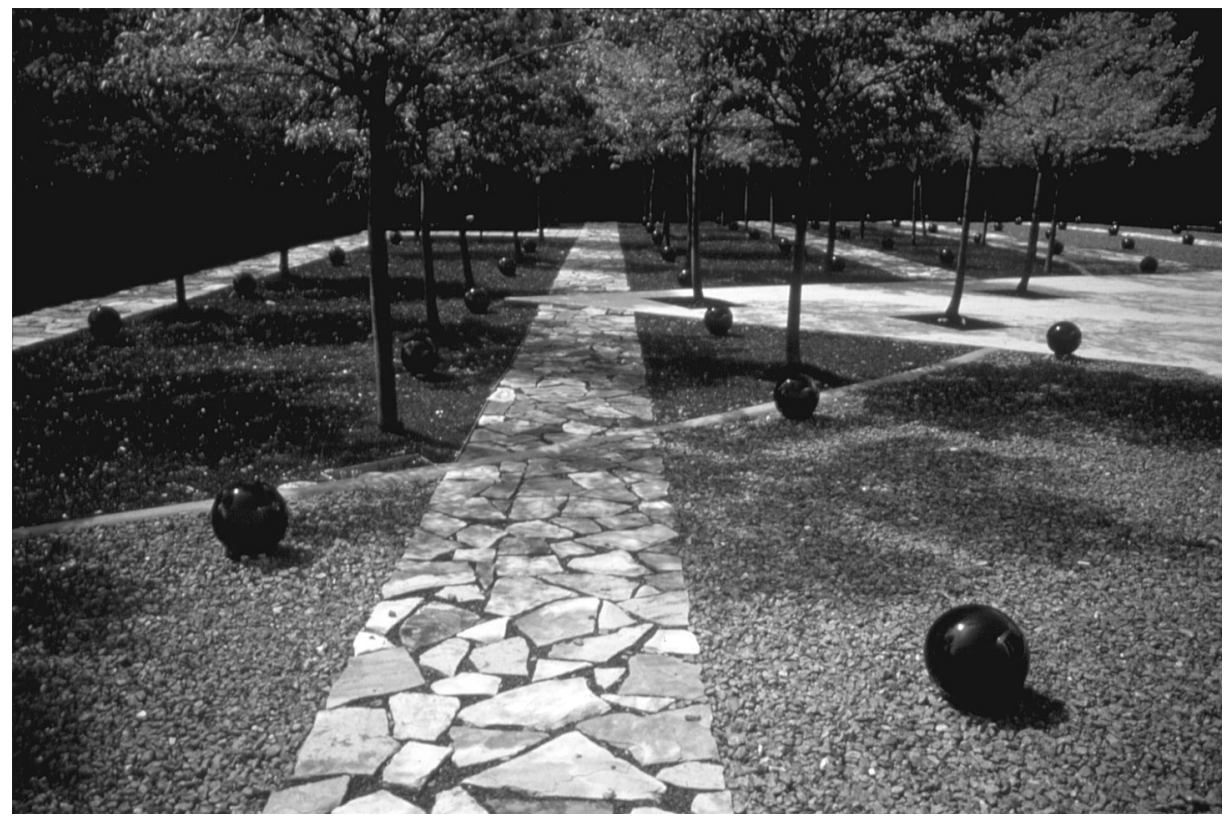

Figure 1. Center for Innovative Technology, Herndon, Virginia, 1988. Martha Schwartz. Mirror ball garden. Photograph by Marc Treib.

painting, before it ever represented any subject external to its physical dimensions, was essentially a question of marks made upon a canvas. By extension, the paintings that most clearly manifest that definition-free of the burden of mimesis-should be more highly regarded. This led to a quest for "flatness," which remained a central concern of painting for decades after World War II. ${ }^{5}$ In landscape architecture, this theory would argue for concentration on spatial, material, and horticultural invention more or less free from the directives of social and environmental issues.

Rather than structure, space, and pattern as content, deeper works may result from using these vehicles to embody other types of content, among them the understanding and judicious application of ecological processes (including the immediate as well as larger site over time), and the regard for humans singly and in groups, both contemporary and in the future. The manner in which the designer addresses these factors may also elevate a physical statement of these concerns, alone or together, to a poetic level. It is admittedly a difficult task, and without question, no work is ever perfect in all respects. Nonetheless, several landscape architects currently in practice have undertaken designs with these considerations at their core. As examples I cite several projects by Hargreaves and Associates in the United States, and Georges Descombes and Dieter Kienast in Switzerland.

\section{Landscape, Form, and Content}

In the last few decades, the pendulum that traces the evolution of design styles has once again swung regularly between formal and more naturalistic manners. This should come as no surprise, of course. Since the very origins of landscape architecture as a defined practice, the manner in which we construct landscapes has featured these alternating models, with an almost complete gradient of variations in between the two extremes. ${ }^{6}$ The Garden of Eden, for example, is normally conceived as a natural landscape, albeit bounded by an excluding wall. And from its very origins, agricultural production has required a more efficient organization of planting and irrigation, lead- 
ing to landscapes in which the human hand has been more, rather than less, apparent.

While convenient for historical studies, this two-part division into formal and informal is only partially useful. For one, it greatly favors the sense of sight, undervaluing the significance of botanical or cognitive processes. The power of garden design as visually perceived, it would seem, instead rests in the overall scheme and the balance of the garden's elements, as well as the collisions and transitions among them. There is no formality or informality in isolation, as there is no concept of nature free from a concept of culture. Never is the question of formal and informal one of simple opposition, nor a simple choice of one over the other. Most importantly, we need to question to what extent the forms, the space, and the manners of realizing landscape design truly embody its content.

Although there are many problems in assigning merit to landscapes only on the basis of form and space, even the most logocentric critic must admit that it is just these aspects which ultimately confront human perception. As such, they seem virtually impossible to avoid. ${ }^{7}$ It is useful to further comprehend the reasons behind formal manufacture, and here art critic Dave Hickey's discussion of the painter Brigit Riley is instructive. Hickey distinguishes between perceptually- and cognitively-intended art works, further dividing the more formally instigated category into two groups of varying value. He discusses the three categories in this way:

[T] he rhetorical-empirical brand of 'behaviorist modernism' practiced by Bruce Nauman and Richard Serra, for whom, as for Riley, the manipulation of material and formal means is directed toward the evocation of a local, cognitive-kinesthetic experience that is quite distinct from linguistic communication (which presumes that the work of art bears a message) and formal appreciation (which posits the work of art as a dead thing, artfully manipulated and sensitively perceived). ${ }^{8}$
Do formally conceived landscapes serve a greater purpose- "local, cognitive-kinesthetic experience," for example, or do they exist only for "formal appreciation (which posits the work of art as a dead thing ...)?" A painting or a sculpture tends to be more finite than a designed landscape, no matter how perfectly maintained it may be. If perception is the primary vehicle for understanding, we also need to consider aspects of cognition, which are equally, if not more, crucial for maintaining interest and pleasure-and for evaluating landscape merit. This mental discernment distinguishes between the manner of making a landscape and how we think about that landscape. It again raises the issue of landscape content.

Thus, we might gauge the content of landscape design along three axes: the formal (which includes space, form, and materials); the cultural (which includes history, social mores, and behavior); and the environmental (among them ecology, topography, hydrology, horticulture, and natural process). Of these-and I admit here to a personal bias-the formal serves best as a means to an end rather than an end in itself.

The cultural landscape histo- rian John Brinckerhoff Jackson defined landscape as: "a space on the surface of the earth; intuitively we know that it is a space with a degree of permanence, with its own distinct character, either topographical or cultural, and above all a space shared by a group of people." ${ }^{9}$ This definition suggests that basic to all landscapeswhether destined for functional, contemplative, or entertainment purposes-is the presence and accommodation of human beings as individuals or in society, and a landscape that serves their physiological or psychological needs.

In addition, the conditions particular to the location also inform the making of a designed landscape-although I would not go so far as to say they truly determine an approach. Thus, landscape design - consciously or not-always reflects contemporary values and attitudes; there is no one way to create a landscape, even at a particular time. Creating places in an arid landscape, for example, could follow several paths. The designer could accept the limitations of the desert and frame existing topography and vegetation, as did Frank Lloyd Wright in 1938 at his own home and studio Taliesin West in Arizona (Figure 2). Or the desert could

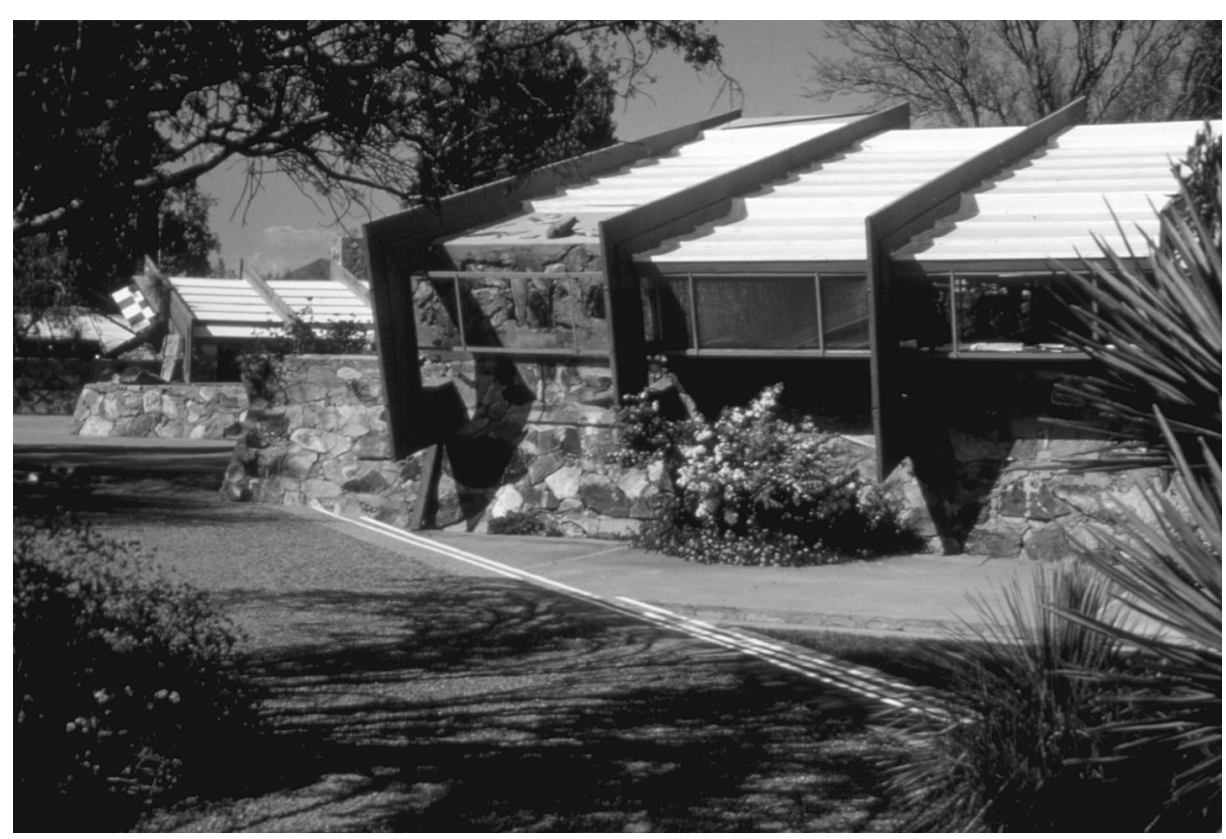

Figure 2. Taliesin West, Scottsdale, Arizona, 1938+. Frank Lloyd Wright. Photograph by Marc Treib. 


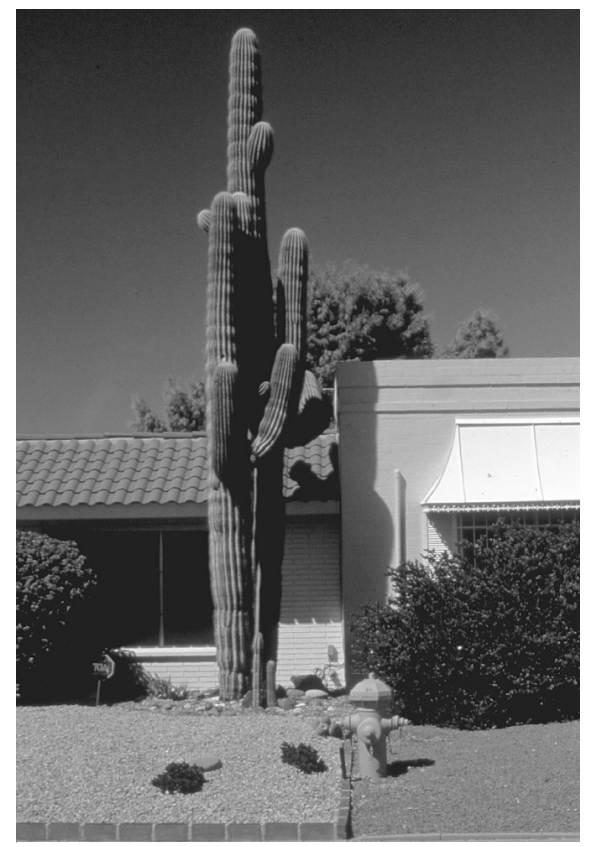

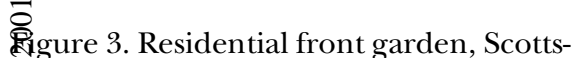
桂ale, Arizona. Photograph by Marc Treib, B. 998.

i̊

Qe approached more abstractly, as nु-on-professional garden makers often do (Figure 3) in suburban हैhoenix. ${ }^{10}$

But one needn't accept the limiิs imposed by local conditions: a Ge could also be conceived as ăvehicle to transcend the constraints off everyday life. The idea behind the paradise garden, for example, has alWैays been to escape what nature ofrs, to develop irrigation systems ब्ञnd horticultural methods that Fould allow landscapes to deny the arictures of local conditions. In the Tore of many peoples, paradise proposes the antithesis of where a people live, as Yi-Fu Tuan has shown in his book Topophilia. ${ }^{11}$ To those living in cold climates, paradise is warm and lush; to desert folk, it is lush and well-watered.

The exquisite Patio of the Oranges in Seville derives from the paradisiacal idea, where the golden fruit and the enjoyment of shade derive from an adroit management of irrigation (Figure 4). There, the technique - the formal organization, the details, the true design-is more obvious than in evocations of paradise based on a more naturalistic model.
Without doubt, we do read and appreciate this garden, like many flower gardens, on formal terms alone. But this initial pleasure may be heightened by sensing the garden through more than one dimension. As landscape architects or artists or architects we may appreciate more rapidly the beauty with which this religious courtyard has been made. This creates somewhat of a dilemma, with questions such as those that opened this essay. How do we weigh the value of a designed landscape?

As we cannot accept any simple opposition of formal and informal to categorize landscape form, so we can not evaluate landscapes using any one of these three sets of considerations taken in isolation. All three sets of concerns: cultural, environmental, and formal (here "formal" describes the properties of form and space rather than the style) - warrant consideration. Social accommodation without a consideration of the place may lead to uncomfortable landscapes. Surrender to the restrictions of climate may produce landscapes devoid of beauty or human appeal. Visual beauty alone risks the danger of being sterile and removed from life. Engaging the full trio of concerns both to create and evaluate landscape architecture offers far greater potential. Cultural concerns, as translated into planning for use, need to be taken quite broadly. By Western standards, gardens in Japan such as those created for the Zen sects, appear to have no function (Figure 5). Yet contemplation, dreaming, and aesthetic appreciation at times are all valid landscape functions in and of themselves. On those grounds, the dry gardens perform handsomely as cultural vehicles.

With this proposition of values, the focus now shifts to several selected tendencies in recent landscape design practice. My principal concern here is the escalating appreciation of landscape design via the photograph or cinematic image, and more recently, as digital representation. That we now more often look at representations rather than actual landscapes has allowed formalist designs to achieve great prominence. Other aspects of the landscape, more subtle or less easily conveyed in photographs and publications, have suf-

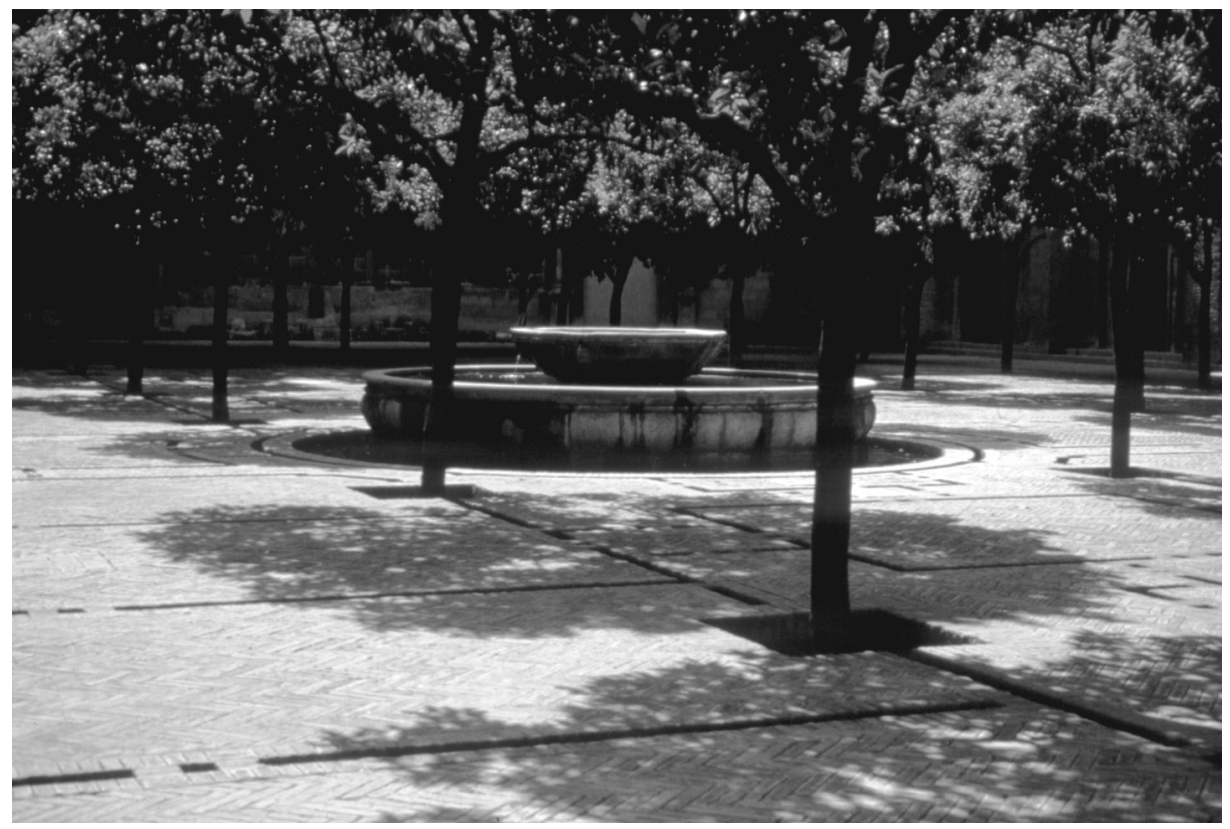

Figure 4. Patio of the Oranges, Seville, Spain, Sixteenth century+. Photograph by Marc Treib. 


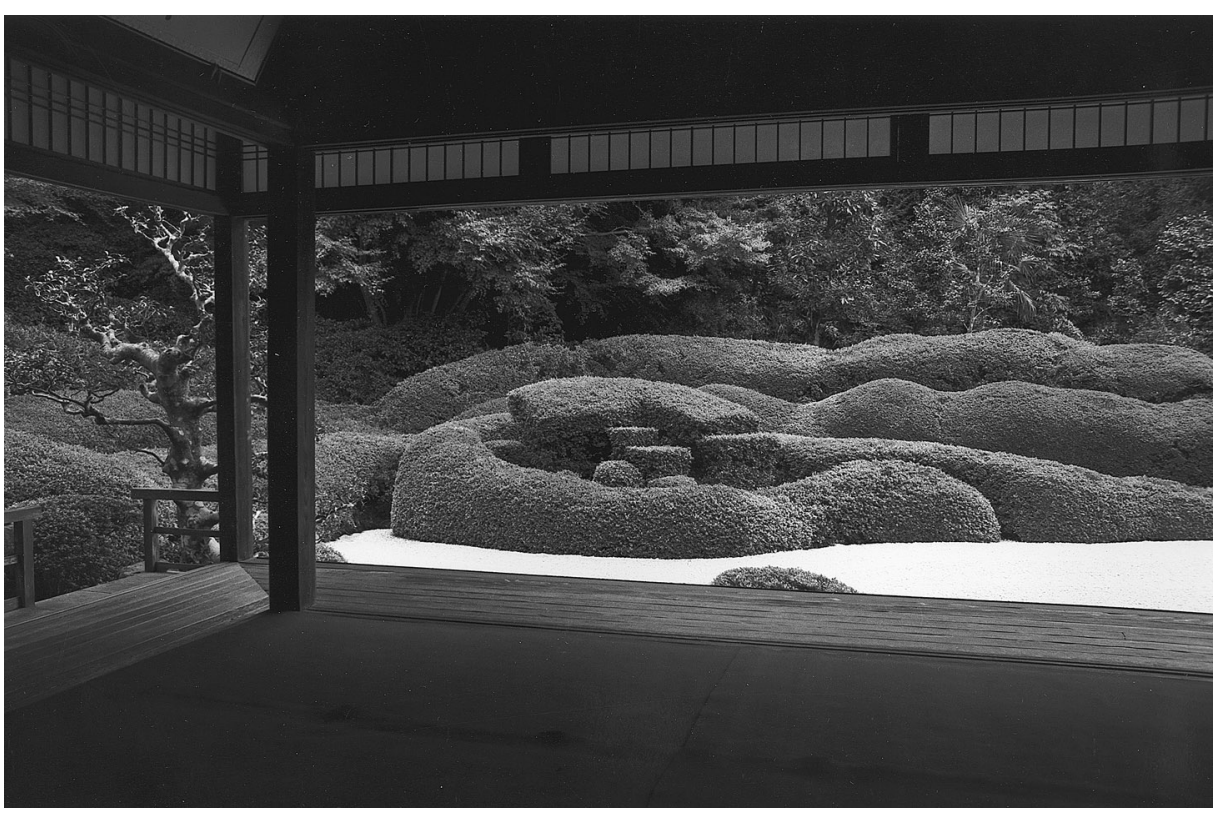

Figure 5. Daichi-ji garden, Shiga Prefecture, Japan, Seventeenth century. Photograph by Marc Treib.

fered neglect. ${ }^{12}$ As a result, we often reward form-as-content (which, as noted above, it can be), rather than form and space as what the painter Ben Shahn once termed "the shape of content." 13

Discussing content questions the medium by which most landscapes are known today: the photograph in publication. In many cases, it is the visual appeal of the landscape-or even the appeal of the photograph alone-that seduces the viewer. There may be no appreciation for the managing of the constraints that guided the design and coerced the true brilliance of its solution. Since viewers of the photograph rarely experience the actual landscape, the experience of the photograph substitutes for the experience of the place. As a result, we "filet" the content by appreciating only the look of the design.

In some ways this may not be a completely negative practice, as even in photographs new ideas enter the landscape discipline and practice. On the other hand, engaging images of landscapes by Peter Walker or West 8 or Martha Schwartz may be copied in almost every country on Earth, with little formal idiom. Perhaps. The danger of blind copying, however, is that it tends to replicate patterns and forms without any real consideration of the local conditions or the consequences of such replication. Perhaps a grid of squares or lines or diagonal planting beds just doesn't make much sense in the Swedish forest or a sub-Saharan desert. Too often, we are skillful at copying forms as portrayed in photographs without investigating to sufficient depth the ideas behind them.

How can we balance these factors? How do we acknowledge contemporary needs and contemporary programs? How can we interpret lessons from histories, both local and exotic? How do we address ideas of contemporary culture, or related art forms and thinking in other disciplines? Only those most conservative individuals would argue that landscape architecture should not advance with its culture and with its times. There still is merit in the modernist belief that only rarely does a historical answer serve us as a precise model for contemporary life, although history does aid our understanding of the present and the future.

A highly selective sample of work from the very recent past may help answer some of these questions.

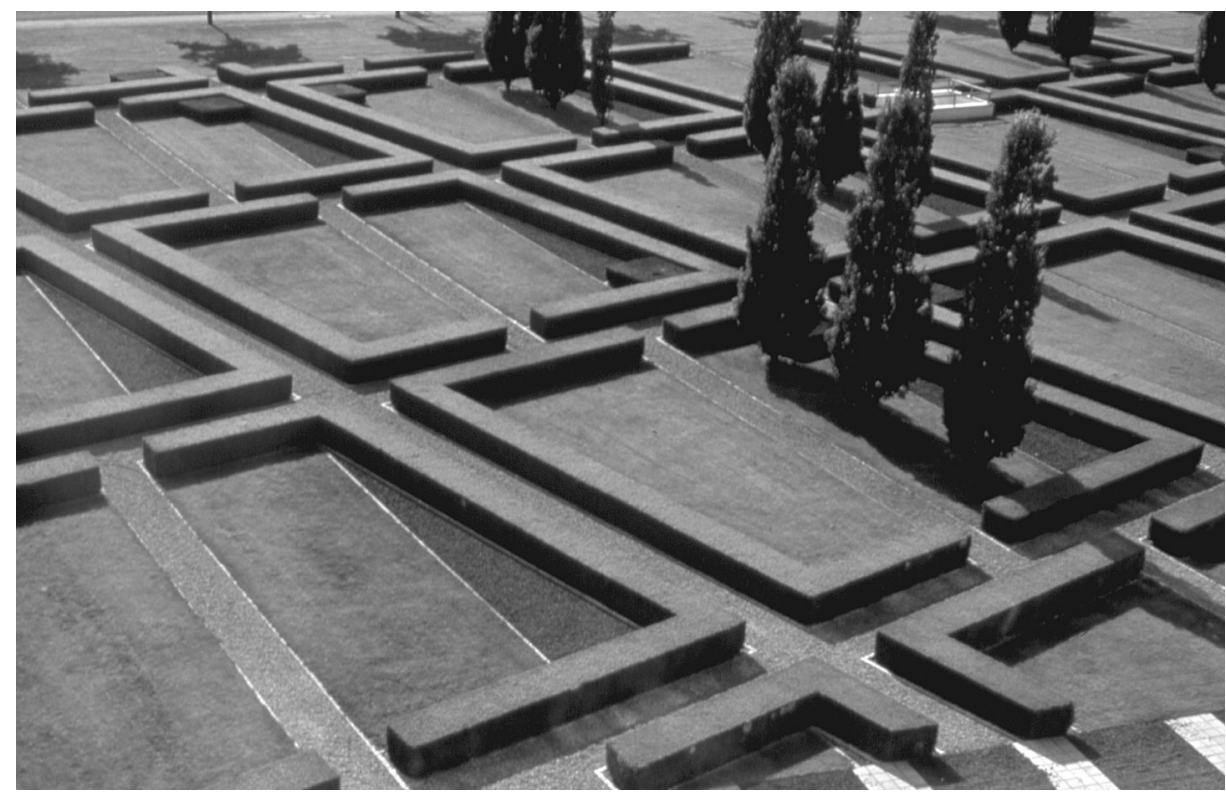

Figure 6. Kempinski Hotel, Munich, Germany, 1994. Peter Walker Partners. Photograph by Marc Treib. 


\section{Formalist Triumphs}

Somewhat in reaction to the then-prevailing analytical and usually naturalistic manner that stemmed from the writings and practice of Ian McHarg, a group of landscape architects in the 1980s and into the 1990s came to rely to a large degree on formal pattern. Peter Walker in the United States and later West 8 in the Netherlands (and followers worldwide) have utilized stripes, grids, rotated geometries and regularity to structure their designs (Figure 6). ${ }^{14}$ Even when addressing ecological requirements, these landscape designs are in many respects return to the parterres characteristic of the seventeenth-century French gardenexcept that now the parterre and the garden as a whole are rendered congruent.

A number of these works, alas, arre more stimulating in photographs 解an in reality. The photograph suEerimposes a rectangular frame gpon the landscape, against which are composed the linear rotations or degular bed plantings. ${ }^{15}$ The photograph is a fragment that is forced to represent the whole, like the synec-

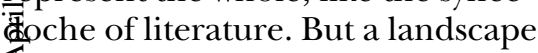
is not a fragment: it is a whole, and at

\section{苛}

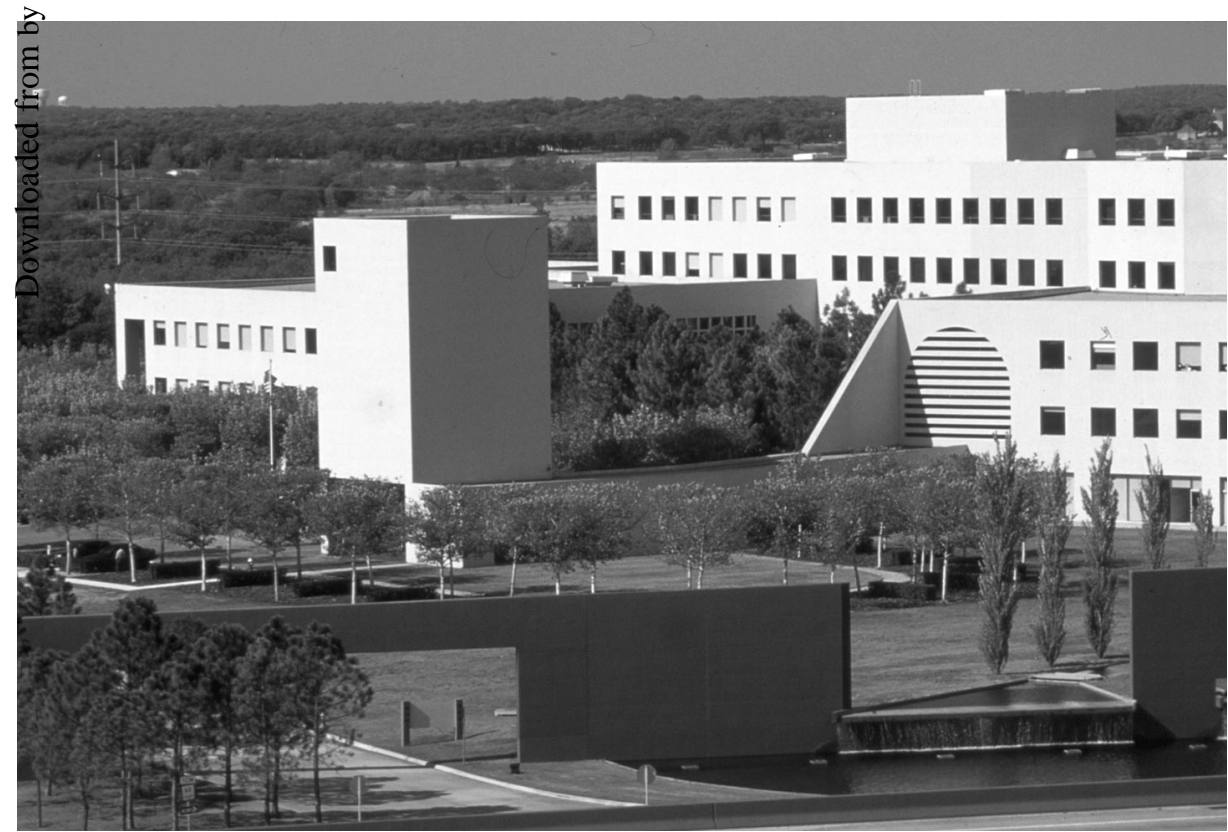

Figure 8. IBM Southlake, Solana, Texas, 1989. Office of Peter Walker Martha Schwartz. View of the east campus. Photograph by Marc Treib.

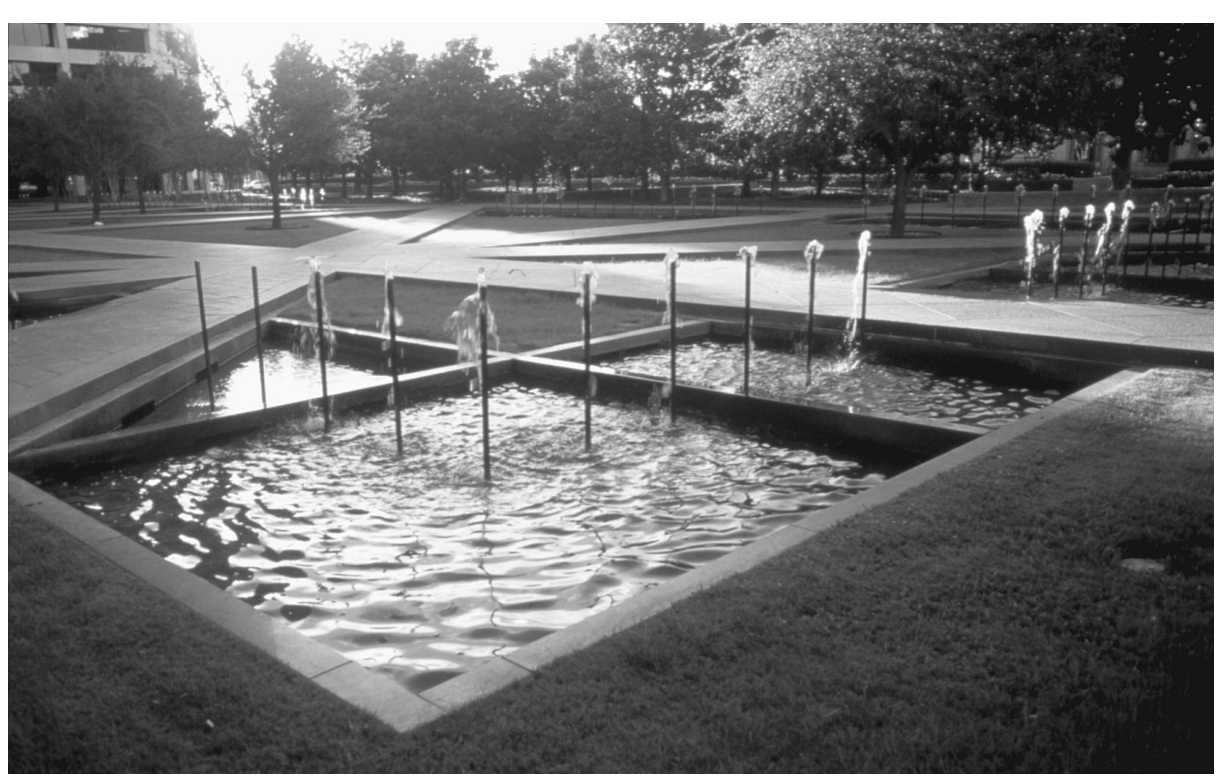

Figure 7. Burnett Park, Fort Worth, Texas, 1983. SWA/Peter Walker. Photograph by Marc Treib. times these designs maintain our interest only at small scale for short periods of time. At Burnett Park in Fort Worth, Texas, for example, the overall pattern is arresting in its overlays of orthogonal and diagonal lines, and their relation to the structure of the park as a whole (Figure 7). ${ }^{16}$ The pattern, which in this case was said to derive from pedestrian movement across the park, on first look, appears to be a dynamic play of oblique lines. Yet in the end, the net experiential effect is quite static. Little draws us from point $A$ to point $B$ because point $\mathrm{A}$ is just about the same as point B. In this sense, the more extreme examples of formal patterningespecially those that remain flat, without true spatial consequencesdemonstrate little regard for the human body, mystery and appeal, or for senses other than vision.

The use of pattern has had its successes, however, and it is not a proclivity so easily dismissed. Two examples of landscapes from the late 1980s stand as the high points of recent formalism. The first comprises the landscapes designed for the IBM community at Solana, outside Dallas, Texas; the Office of Peter Walker and Martha Schwartz were the landscape architects (Figures 8 and 9). The architect for the Solana IBM campus and the town center was Ricardo Legorreta; Mitchell Giurgola designed the West Campus. The power of the IBM scheme derives from graphic structure's directing spatial development rather than remaining 


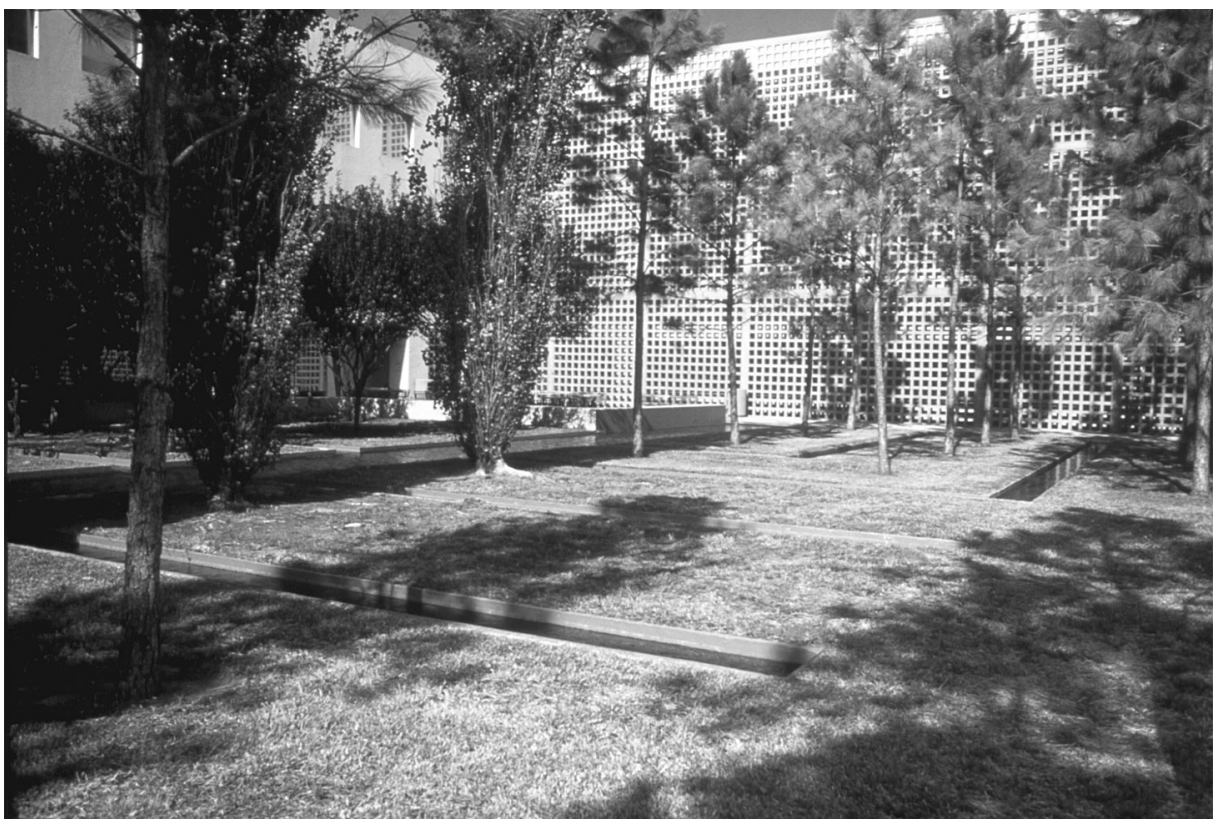

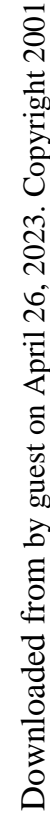

Figure 9. IBM Southlake, Solana, Texas, 1989. Office of Peter Walker Martha Schwartz. Canals and plantings as elements of the pattern. Photograph by Marc Treib.

a two-dimensional figure alone. In the main office complex, for example, the architect convoluted the perimeter of the building blocks, using courtyards as transition spaces between the landscape of the architecture and the architecture of the landscape. These courts function as hinges that pivot the eye and the body from inside to outside and vice versa. Zones of varied shades and enclosure result, providing comfort during outdoor occupation, and visual pleasure throughout the year. Legorreta's vibrant color palette intensifies the architectural presence and heightens the visual articulation by setting yellow and purple planes against the greens of the vegetation and the blues of the canals.

This is the key: at Solana, pattern generates and structures its three-dimensional consequences and becomes spatial; architecture and landscape architecture enfold within a charged equilibrium geometrically conceived, formal in their pleasures. However, this aesthetic pleasure-as noted above-also derives from modulating climate and light for physical comfort. Success is measured along more than the aesthetic axis alone, even if it may not have been the de- signer's primary concern.

The mid-1980s plaza/terrace for the North Carolina National Bank (NCNB) in Tampa, Florida is more rigorous than the Solana landscapes in using purely geometric structure (Figures 10 and 11). ${ }^{17}$ Here
Dan Kiley superimposed several layers of gridded pattern to generate a complex chessboard for trees and ground covers rather than for rooks and castles. The predominant grid positions a field of Washingtonia palm trees upon the ground plane, which is in fact the roof of the parking garage below. Against this orthogonal organization sweep clumped plantings of crepe myrtle that bloom a vivid pink in springtime. The trees appear irregularly spaced, but in fact follow judicious placement on a smaller-scaled grid. The ground plane demonstrates the project's most complex patterning by far, composed by alternating strips of paving and zoysia grass. In the design of the office tower, which the terrace serves, architect Harry Wolf utilized the proportional system of the Fibonacci numbers to modulate the proportions of the architecture. Kiley extended this proportional thinking into the garden, using these progressions to generate the varying balance of grass to paving from the bank to the far extant of the terrace. This admittedly highly, almost maniacally, structured effect produces a complex, though equilibrated, composition whose readings

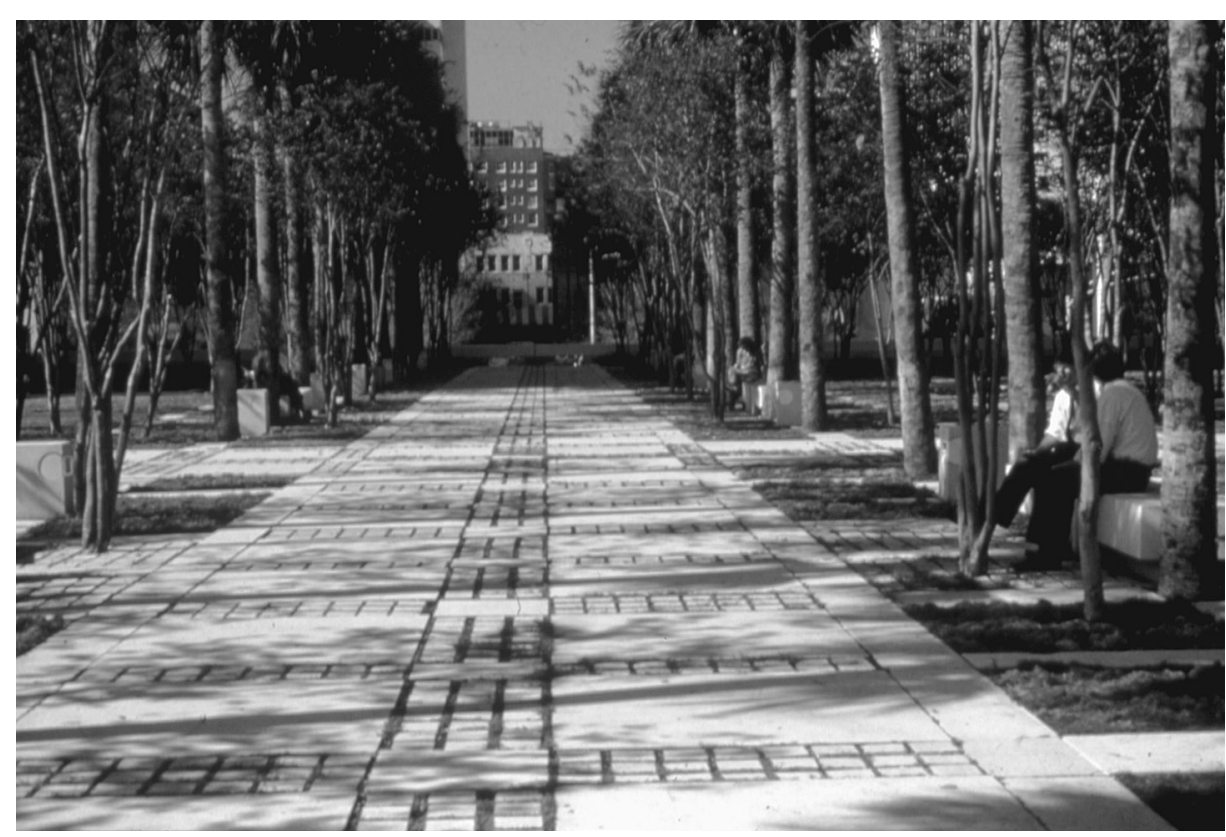

Figure 10. NCNB Bank Terrace, Tampa, Florida, 1988. Dan Kiley. Photograph by Marc Treib. 


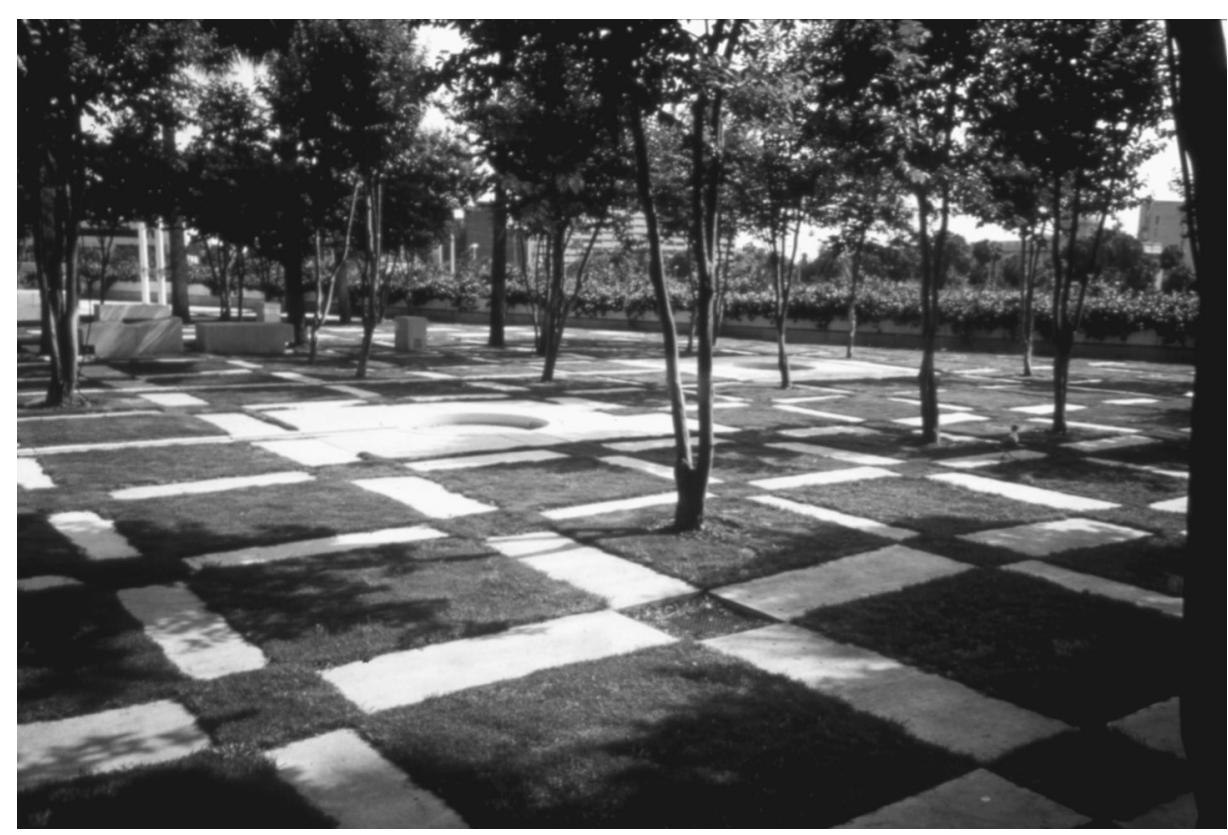

䍏gure 11. NCNB Bank Terrace, Tampa, Florida, 1988. Dan Kiley. Photograph by Marc Treib.



continually change with the visitors' position.

ธิ่ Water creates the garden's fourth layer. Glass roofs the entry corridor to the parking garage. In its Early years, the water that filled this rof created a canal that fed a series \&f rills and fountains that penetrated

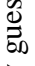

구

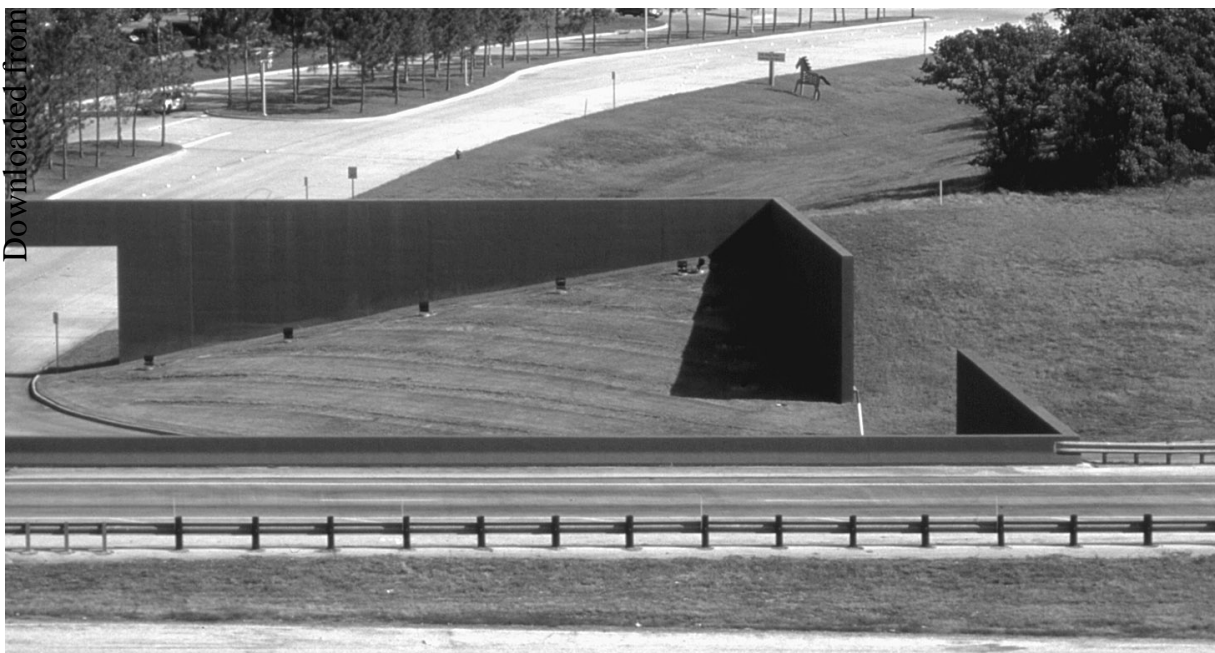

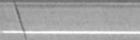

Figure 13. IBM Southlake, Solana, Texas, 1989. Office of Peter Walker and Martha Schwartz. Freeway overpass and entrance to the east campus; banked earth with stripes in mid-distance. Photograph by Marc Treib.

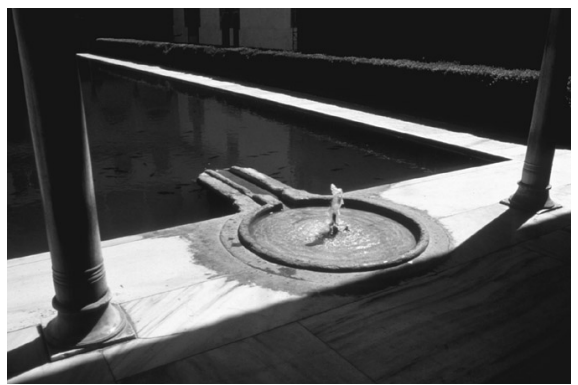

Figure 12. Court of the Myrtles, The Alhambra, Granada, Spain, Fourteenth century+. Photograph by Marc Treib.

references, through Kiley's rigorous geometries and masterful play of linear elements against those more massive-and more importantly perhaps, the development in space of the four layers of the vegetation and water-a garden that is perceptually rich results. There is little doubt of its contemporaneity, and yet there is little that does not suggest some historical, classical precedent. This is the magic of the Kiley manner, and it demonstrates that the past always maintains its relevance to the present as a source of learning through discerning transformation.

Despite the appreciation and enjoyment of landscapes such as these, problems do result from using pattern-making as the basis for landscape design. For example, varied orientations or slopes require different planting solutions-and yet the continuity of the pattern demands a repetition of similar elements. At the powerful walled entrance gateway to the Solana complex, for example, the four slopes face four different directions; and the tops of the hills have different drainage conditions than their bottoms (Figure 13). As a result, it has proven difficult to maintain the shrubs equally on four slopes in order to preserve the pattern of the striping. ${ }^{18}$ Perhaps greater consideration of these factors would have modified-and conceivably invigorated - the pattern; or further study may have determined that arrangements of rocks or gravel 
would have been the best approach to constructing the stripes. The two methods-formal and ecologicalare not antagonistic, unless one of these is employed with little regard for the second.

Horticulturists have noted the ever-present danger of planting trees of a single species. If one should fall ill, all its neighbors may be tainted and threatened. And if too many die in one area, the pattern is destroyed. This, too, has remained a constant threat to the Solana landscape.

Despite these cautions, however, the success of the Solana and Tampa projects demonstrates the sizable potential for these architectural landscapes, if the means to maintain them are available. They emphatically remind us that the formal tradition will not disappear, and that it can achieve renewed vigor in contemporary times through influences such as minimalist art, mathematical progressions, and even historical reference. The problems with the selection of tree species, one would believe, can be solved through shrewd plant selection. More critical is the continued need for focusing on geometric structuring that unfolds as truly threedimensional and structural rather than as pattern making which begins and ends as a flat surface.

The lack of concern for habitable spaces raises issues about intention and content in landscape architecture. As I proposed earlier, could we not agree that human occupation and use are the content of landscape design, and that nature and ecological process constitute the matrix in which we create these new terrains?

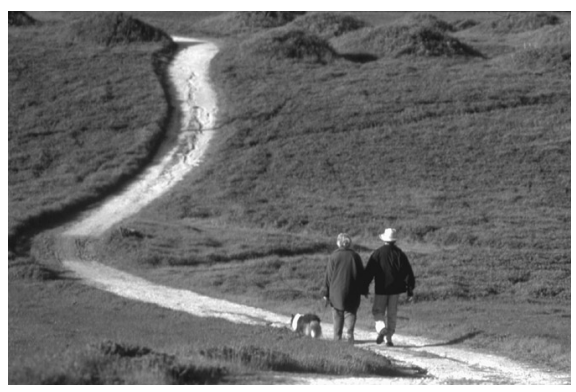

Figure 14. Byxbee Park, East Palo Alto, California, 1992. Hargreaves Associates. Photograph by Marc Treib.

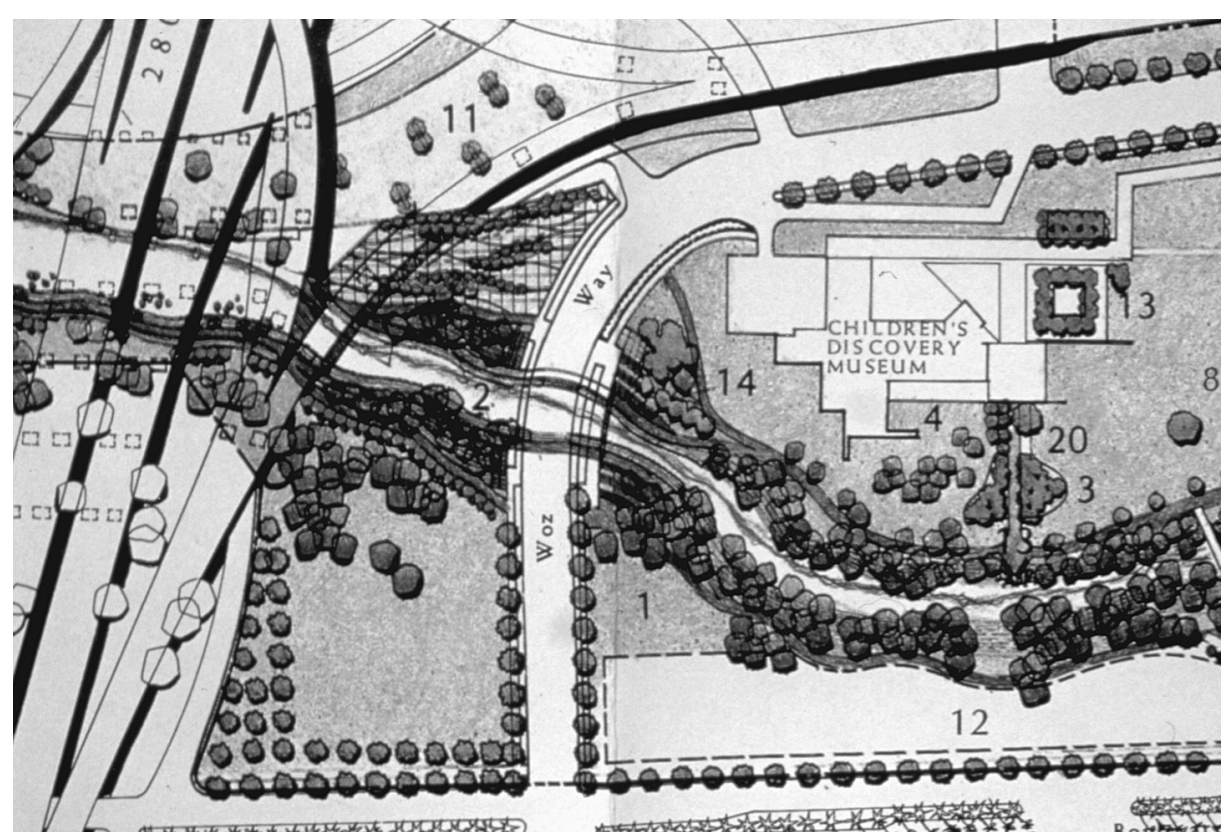

Figure 15. Guadalupe River Park, San Jose, California, 1988-96. Hargreaves Associates. Plan. (Courtesy Hargreaves Associates.)

Landscape architecture thus becomes the compounding of these two aspects into a legible cultural expression, using the formal means we call style.

\section{Natural Process as Art Form}

The work of Hargreaves Associates, based in San Francisco and Cambridge, Massachusetts, exemplifies a heightened interest in form developed from natural process and human use, especially in their designs for a series of waterfront parks. The land for Byxbee Park, located south of San Francisco on the western shore of the bay, comprised garbage and earth fill, in some places measuring more than fifty feet in depth (Figure 14). The site, which was intended to become much-needed recreational land, was thus the product of human hands and built on human waste. The governmental sponsor for the park's hundred odd acres stringently restricted modeling of the earthen contour. To stabilize the putrefying garbage below, a meter-deep cap of soil and clay was applied, with a flame perpetually exhausting the methane collecting beneath the ground. Because it was believed that any rupture in the earthen topping might allow the escape of noxious gas, no trees were planted. ${ }^{19}$ Because seepage might percolate pollutants into the water table below, irrigation was precluded. These constraints directed the designers' attention to land contour as the principal design feature and fostered a respect for native species of grasses, completely dependent on rainfall for their nourishment, they were allowed to turn brown during the dry months of the northern California summer.

Despite problems of the fragmentation of the various design features, as a complete entity the Byxbee project demonstrates that ecologyand entropy-are not antagonistic to landscape design; quite the contrary, an understanding of environmental forces can stimulate significant innovation. The land artist Robert Smithson called our attention to the aesthetic potential of entropic process as early as 1970s; (the effect of entropy on landscape over time was an important aspect of his thinking). But only rarely have its possibilities informed 


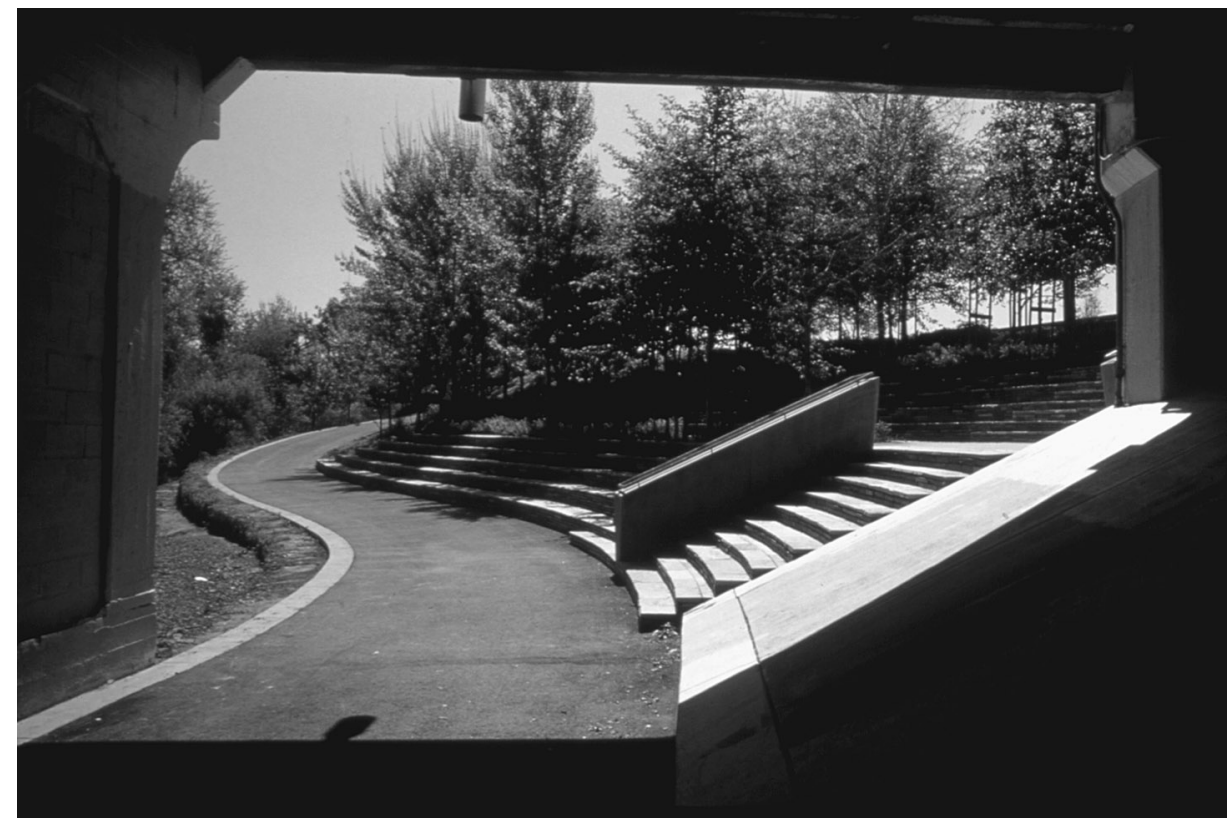

需gure 16. Guadalupe River Park, San Jose, California, 1988-96. Hargreaves Associates. S్ Steps/Amphitheater. (Courtesy Hargreaves Associates.)

离

the design of landscapes rather than \&he making of art. ${ }^{20}$

ก During the last decade, Hargreaves Associates have designed warfront landscapes in San Jose and San Francisco, California, Portland, Öregon, Louisville, Kentucky, and E్ Eisbon, Portugal. Although each deSign rigorously investigated precise focal conditions, as a group the parks aeflect a common attitude toward the ğrocesses and meeting of land and \#ater, reforming them in accord with ơcological, social, and aesthetic paEameters. They also constitute some of the more provocative recent landscape architecture at a larger scale, and in their distinctive approach, resolve conflicting attitudes within the profession.

The Guadalupe River Park, whose master plan dates from 1988 to the present, was intended to reveal San Jose's obscured riverine open space (Figures 15 and 16). Mission San José had been established in the late eighteenth century, as the Spanish established their hold on Alta California. Into this century, the river has remained a green space within the city, but new highways, shifting demographic patterns, and limited access have all impeded its enjoy- mary arteries and constructed major public works including a sports arena, several museums, and the Hargreaves Associates-designed Plaza Park, completed in 1989.

At the threat of inundation and major devastation to the downtown area, the Guadalupe River was itself slated for overhaul by the Army Corps of Engineers. The narrow sliver of a river had frequently flooded its banks - and there was every indication that the increased density of recent construction would only escalate the impact of the next major inundation. Why not use the necessary flood control work to create a three-mile-long park that would bring the people and city to the river and vice versa?

Working with a small army of specialists, the landscape architects developed the general plan and specific designs for the length of the river in the downtown, dealing equally with the "underlay" and "overlay" of the landscape along the banks.

George Hargreaves uses the term "underlay" to describe responses to flood control during times of heavy winter rains or spring run-off; "overlay" comprises the more visually apparent aspects of the design: the re-

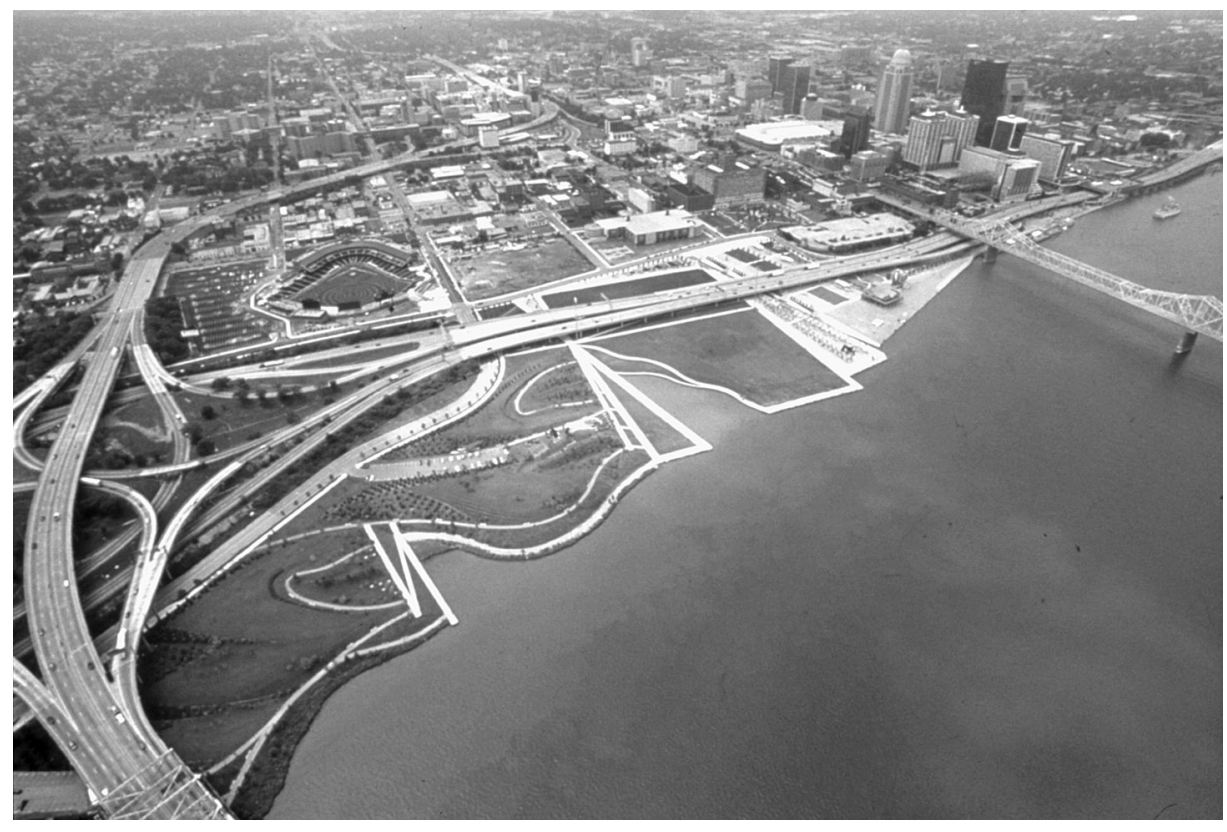

Figure 17. Louisville Waterfront Park, Louisville, Kentucky, 1990+. Hargreaves Associates. Model. Aerial view. (John Gollings, courtesy Hargreaves Associates.) 
forming of the earth and the planting of vegetation. Ordinarily much of this project would be regarded as civil engineering, but in this instance, the landscape architects took an active interest in hydrology and its consequences in form. Their thinking-developed in close coordination with the Army Corps of Engineers-derived from an understanding of water flow, in a sense abstracting and enlarging the consequences commonly formed along the river's banks.

The design models the land in accordance with the necessities of flood control, settings for use, and the need for plantings along the long linear strips of river. The park's design could be described as a series of flows and interruptions, not unlike a river itself. The prevalent terrain parallels the axis of the river, but at key points it is reformed into level planes, slopes, and mounds that parallel the patterning and branching that results from dendritic process. ${ }^{21}$ Both the citizens and the profession have acknowledged the success of the design, although additional phases have been left unimplemented-a common fate for public projects of this magnitude.

The winning park competition entry for the Louisville Waterfront Park addressed the site's despoliation from prior use (Figures 17 and 18). Industry had lined the bank for over a century, removing the land from public access, despite the long tradition of public parks in the city. In the minds of the citizens, the land was an absence, seen only from a speeding car on the elevated highway. ${ }^{22}$ The landscape architects rejected the idea of bringing the downtown to the river, and instead convinced the city to bring the river to the downtown.

Unlike the San Jose park, the Louisville scheme occupies a single shoreline. The land, given its history of industrial use, required detoxification and regrading. Severed from the urban fabric by freeways and bridge approaches, the design proposed replanting trees as links between the park and the downtown. While the scheme appears linear in the plan, the park is actually conceived as a chain of event spaces which vary in their function and form from those that are more open, ceremonial, or event-oriented, to those that are more natural and solitary. ${ }^{23}$

From these more urban functions, the park extends northeastward to more private areas, more "agrarian" in appearance, and more intimate in scale. As conceived, the Louisville Waterfront Park will be a green park, but it will not be a green park in the Olmsted mold. The central green, with its play of skewed rectangles and watercourse, may func-

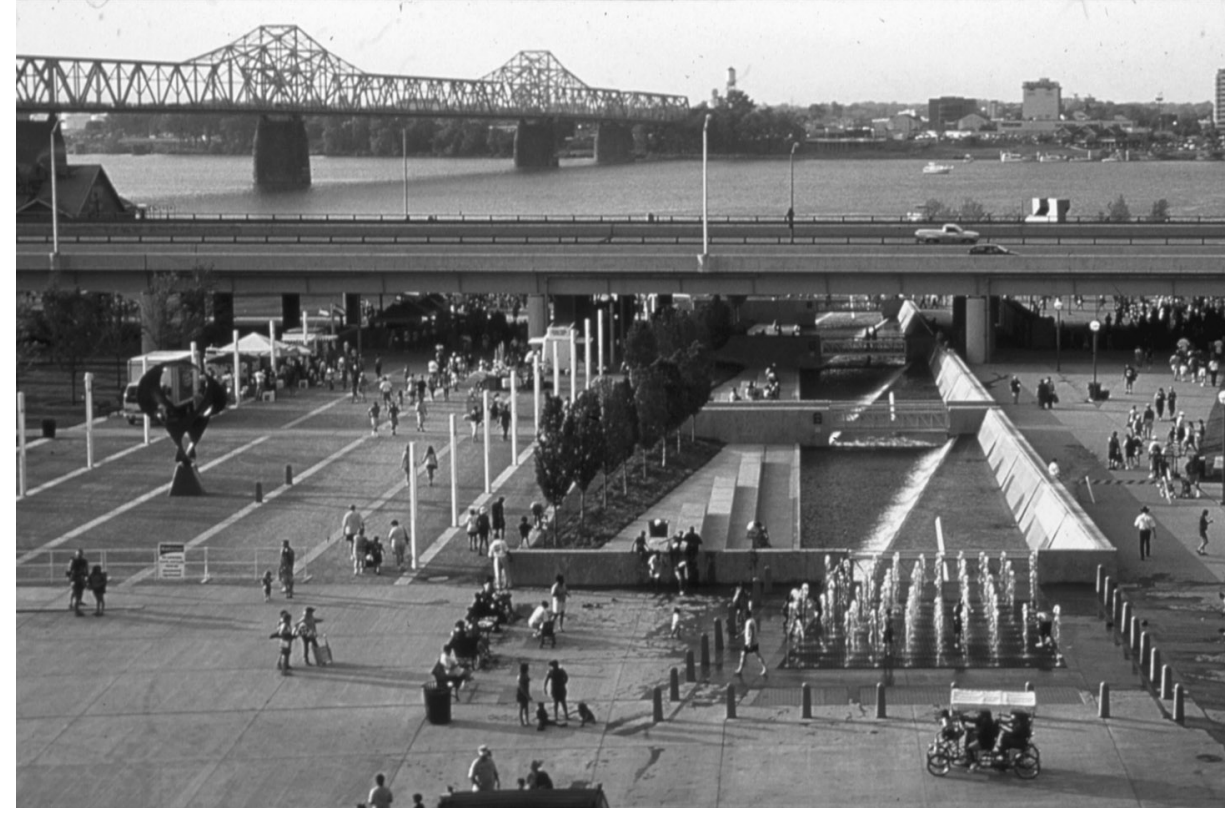

Figure 18. Louisville Waterfront Park, Louisville, Kentucky, 1990+. Central area with water course. Hargreaves Associates. (Geoffrey Carr, courtesy Hargreaves Associates.)

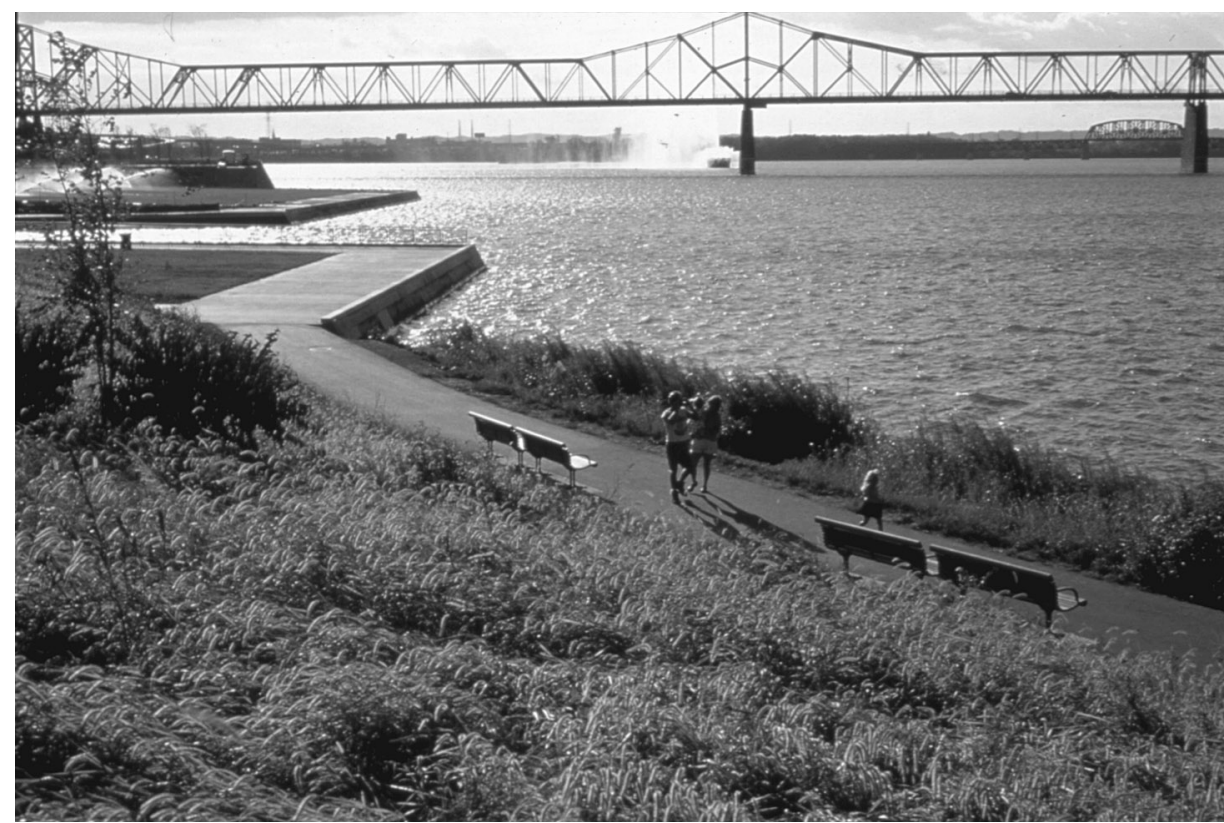

Figure 19. Louisville Waterfront Park, Louisville, Kentucky, 1990+. Hargreaves Associates. The folded edge of the river. (Courtesy Hargreaves Associates.) 


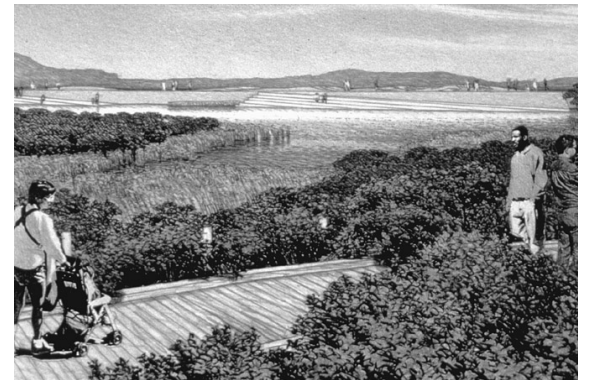

Figure 20. Crissy Field Restoration, San Francisco, California, 2000+. Hargreaves Associates. Projected wetland restoration at maturity.

(Courtesy Hargreaves Associates.)

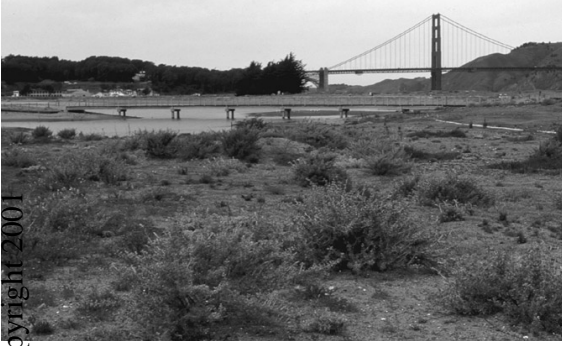

Figure 21. Crissy Field Restoration, San Grancisco, California, 2000+. Hargreaves Associates. The site March 2001.

fCourtesy Hargreaves Associates.)

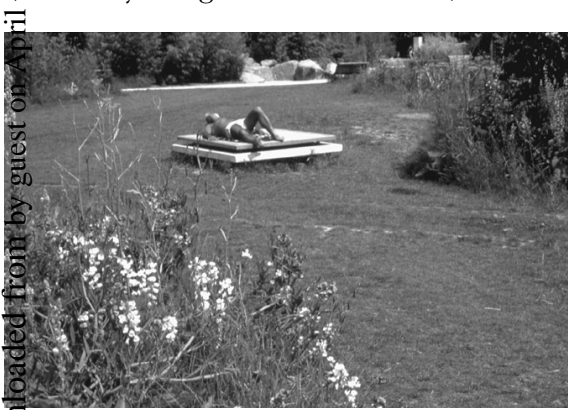

Figure 22. Parc André Citroën, Paris,

France, 1992. Gilles Clément. Jardin en mouvement. Photograph by Marc Treib, 1992.

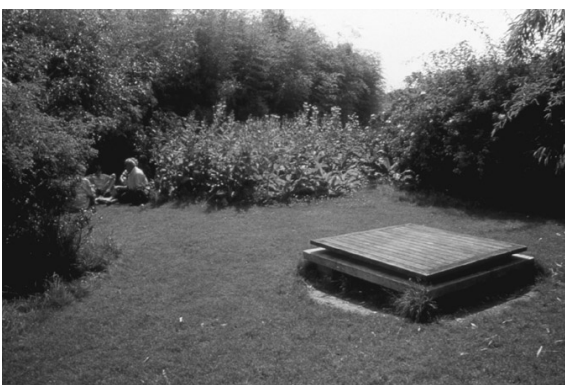

Figure 23. Parc André Citroën, Paris, France, 1992. Gilles Clément. Jardin en mouvement. Photograph by Marc Treib, 2000 . tion at times as a community commons for meetings and concerts; on a daily basis it offers broad open spaces for sports, taking the sun, or even flying a kite (Figure 19). In other areas, mixed plantings of deciduous and conifer trees provide change throughout the year yet guarantee spatial closure at all times. A hierarchy of paths allows for a variety of movement; again the shaped mounds articulate spaces within spaces that offer retreat from the wind in the dales and the exhilaration of a view revealed after a short climb. The new park reclaims as well as reforms; this is a man-made landscape for human pleasure and activity, characteristics Hargreaves freely admits. Considerations of hydrology,

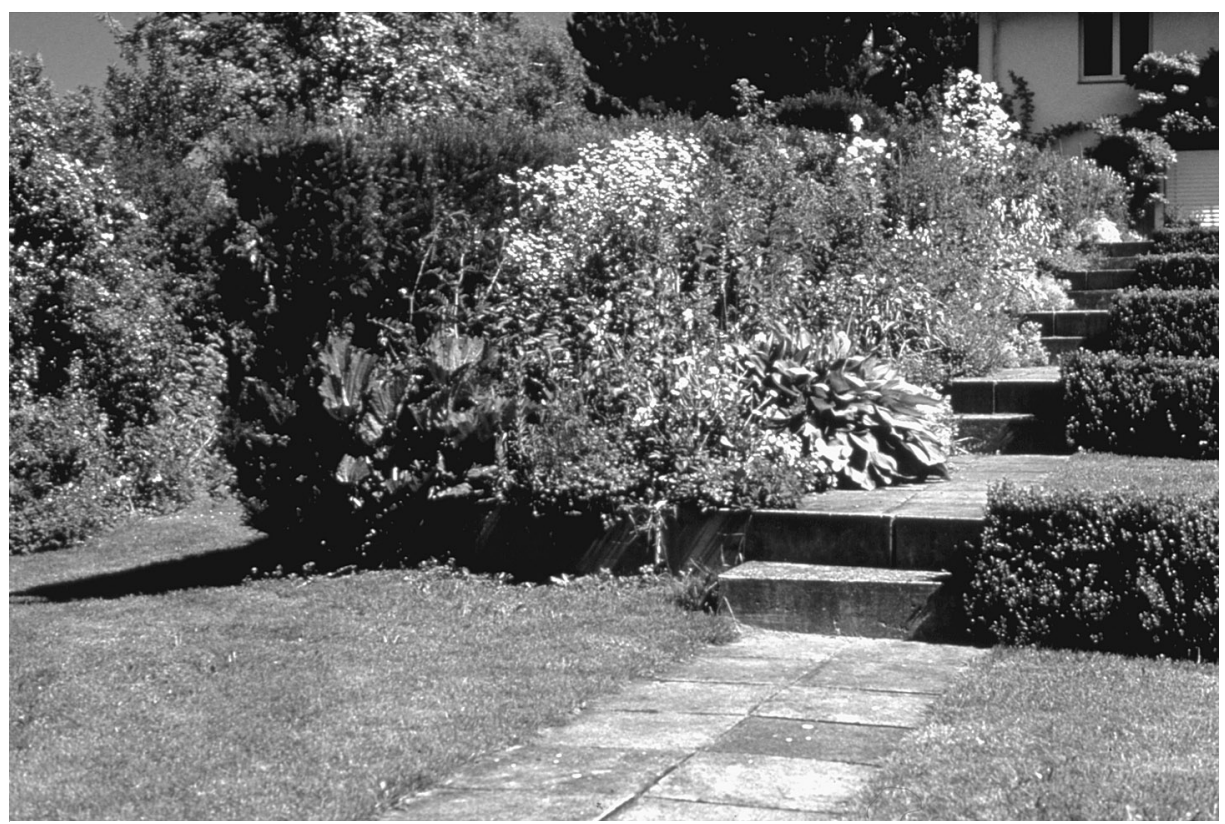

Figure 24. Eschler garden, Uitikon, Switzerland, 1988. Dieter Kienast. Photograph by Marc Treib.

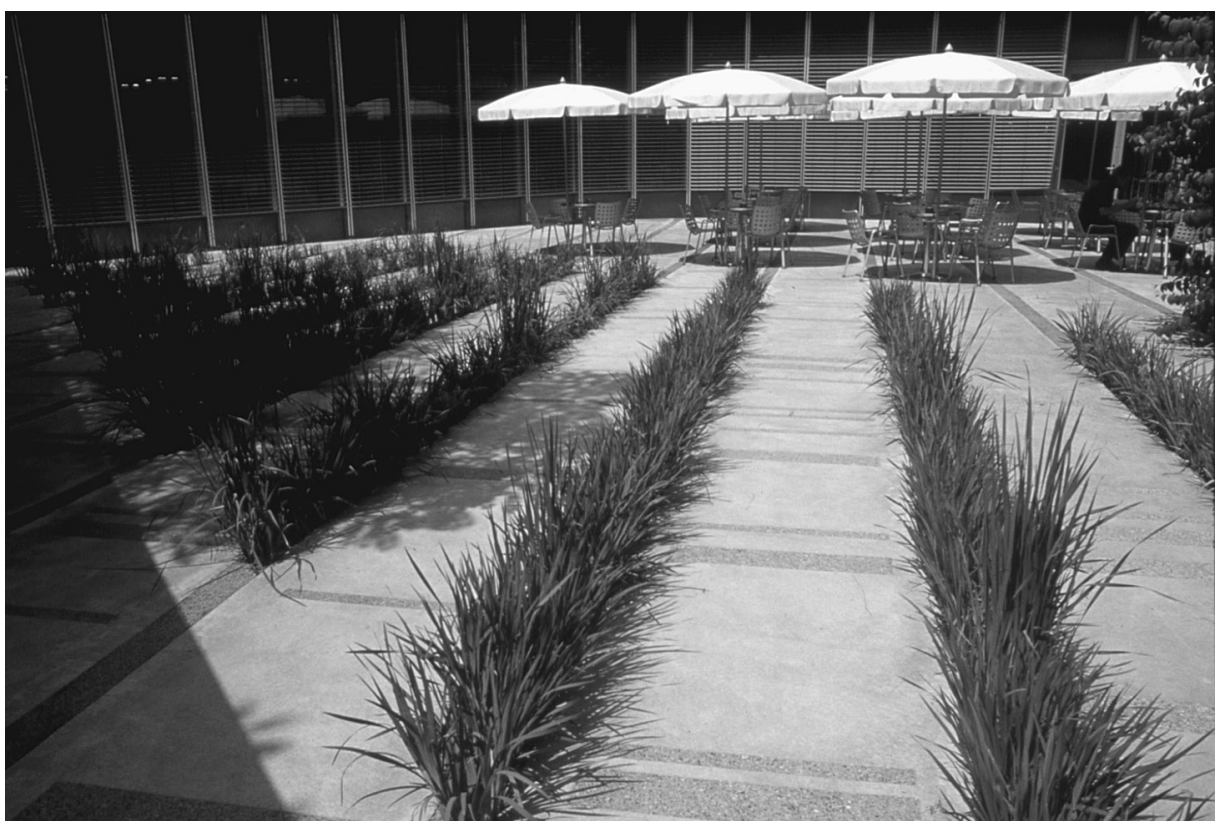

Figure 25. Swiss Re Terrace, Zurich, Switzerland, 1996. Dieter Kienast. Photograph by Marc Treib. 
paired with an investigation of the site's history, have generated a sawtooth land pattern that brings the river deeper into the site. Recalling inlets that existed before the river's regularization; these denticulations also increase the waterfront perimeter and articulate distinct areas of use within the prevalent linear organization. The novelty of the landforms and overall landscape design perhaps postpones direct understanding, coercing the visitor to interact with, and interpret, the park's design as an individual. This, of course, was a lesson of Minimalism in sculpture. This is true abstract landscape design; abstraction that derives from an understanding of its sources in nature but makes no attempt to replicate them. The park is a human construct using natural elements where appropriate.

The first phase of Louisville Waterfront Park has been completed and the succeeding stages are in progress. Paired with the completion of the Guadalupe River project, it constitutes positive prospects for landscape architecture in the future. The current wetlands restoration project for Crissy Field in San Francisco is more sweeping in its scope and more complex in its attempts to mediate the disparate values of its constituents-a set of considerations at least equally complex to those concerning ecology (Figures 20 and 21). Some factions wanted a complete restoration of the wetlands; use for individuals and groups was of secondary importance. Others sought to continue the current primarily recreational activities on the site. And, one would suspect, the designers felt that a contemporary landscape should reflect contemporary aesthetic ideas as well as social and ecological concerns. The resulting design, at least as it stands today-still incompletereflects quite distinctly these three arenas of consideration. ${ }^{24}$ The form of the landscape reflects a design strategy of juxtaposition rather than any single aesthetic entity; an appropriately complex model for landscapes in the contemporary era.

First, the waterfront designs reject the notion of a landscape that emulates nature (unless constraints dictate otherwise); they are intended to be "natural, without being naturalistic." ${ }^{25}$ They are green; they are heavily planted; they engage the water in a very active way, normally increasing the length of the edge where shore meets river. But they do not directly strive to recall or replicate natural forms in the manner of the nineteenth-century Olmsted landscape. Although not the words of the designers, one could argue that even nature herself would never produce a "natural-looking" landscape given the condensed time span of construction. Construction alters the sweep of process, as a stone tossed into a shallow creek alters its movement. The water continues to flow in accord with gravity and geomorphology, but its nature and its rate of change have themselves changed. Could we not regard landscape design as giving form to natural processes constrained by contemporary social and aesthetic conditions, executed in a mere blink in geological time?

These parks by Hargreaves Associates are, without question, designed landscapes from the 1980s and 1990s. While rooted in social use, the varied settings contribute to the whole of the park as a greater entity-they are not a series of adjacent play fields or more significant fea- tures taken independently. These parks evince an art built on history, use, ecology, and, of course, the aesthetics of contemporary form. They take a direction of their own but share parallels with European landscapes evincing similar values.

At the Parc André Citroën in Paris, for example, Gilles Clément installed a jardin en mouvement using a neo-Darwinian attitude in which broad scale seeding was modified over time by the survival of the heartiest species. ${ }^{26}$ As it happens, many of the species seem to have survived and this one quarter of the park is today heavily planted, evident in these images (Figure 22) taken at the time of the park's opening in 1992, and (Figure 23) in summer 2000. For some, perhaps, there is insufficient form apparent in this strategy, particularly as portrayed in photographs. Beyond the camera's frame, however, it is the frame of the park's overall structure, which structures and domesticates this wildness and makes it inviting.

Perhaps more surprising are the ecological ideas that support many landscape designs by the Swiss landscape architect Dieter Kienast who died in 1998. American audiences first encountered Kienast's gar-

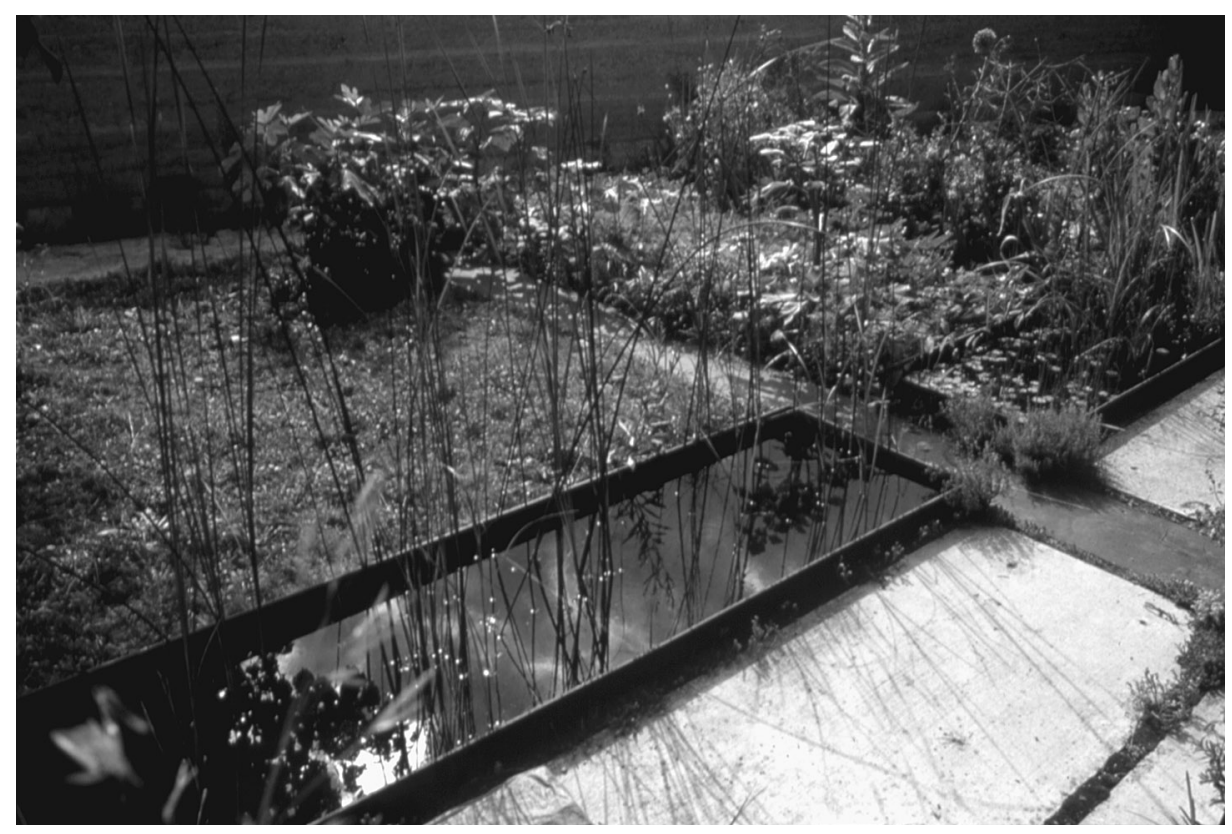

Figure 26. Koenig-Urmi garden, Maur, Switzerland, 1996. Dieter Kienast. Flat steel tanks for aquatic plants. Photograph by Marc Treib. 
dens in a book published by Birkhäuser in $1997 .{ }^{27}$ In photographs by Christian Vogt, the Kienast landscape is black and white, subtly textured and composed, resting serenely under mostly cloudy skies. In reality, however, one encounters vibrancy, life, and ideas of far greater abundance than those captured on the flattened plane of the photograph.

Without question, Kienast possessed a deft ability for making balanced yet quirky compositions, and in some ways his manner conflated the structured spaces of the Italian Renaissance garden with the heavily layered plantings of the English cottage garden-all set in careful repose (Figure 24).

Ecological understanding underlies many of the Kienast gardens, although his ideas are not evident to 曹e photographic eye. For example, 离 the restructuring of the terrace क्रुjea for the insurance company Swiss $\vec{E}$ e in Zurich, clearance for the parkकิ in terrace level above. Kienast in@ined, rather than stepped, the gaved surfaces to collect water run Off, using the gaps between the aavers as drainage channels (Figure \$5). In areas neither intended for șeating, nor draped by the weeping Eatsura trees, the gaps were planted Whith irises almost in the manner of Ëertrude Jekyll's terrace garden at 肖estercombe.

\pm The horticultural properties of \&gigantic collection of plants propelled a garden design for two Eotanists in the hinterlands around Eurich. In their previous garden, the couple had accumulated nearly 500 species of plants: more or less one of each. In 1996, they turned to Dieter Kienast for a new garden that would support aquatic as well as terrestrial species, in a projected number even greater than their then-current collection. The landscape architect described his task as the following: "What does a garden look like to botanists? Moss, loam, solitary bees, handkerchief tree, sand, dragonflies, rushes, gravel, hedgehogs, cucumber, earth, butterflies. How can these thoughts be formed into a garden?" 28 Alongside the house Kienast aligned, in enfilade, a set of flat steel tanks for the aquatic plants that led to the rear garden beyond (Figure 26).

The primary design act for the Koenig-Urmi garden was to divide the soils of the rear garden into four distinct strips: gravel, clay, sand, and loam (Figure 27). Species best suited to each of the soils were planted in the corresponding zone. A field of concrete slabs suggesting river ice breaking with the spring thaw overlaid the structured zones of soil, an antiphonal composition of two dis-

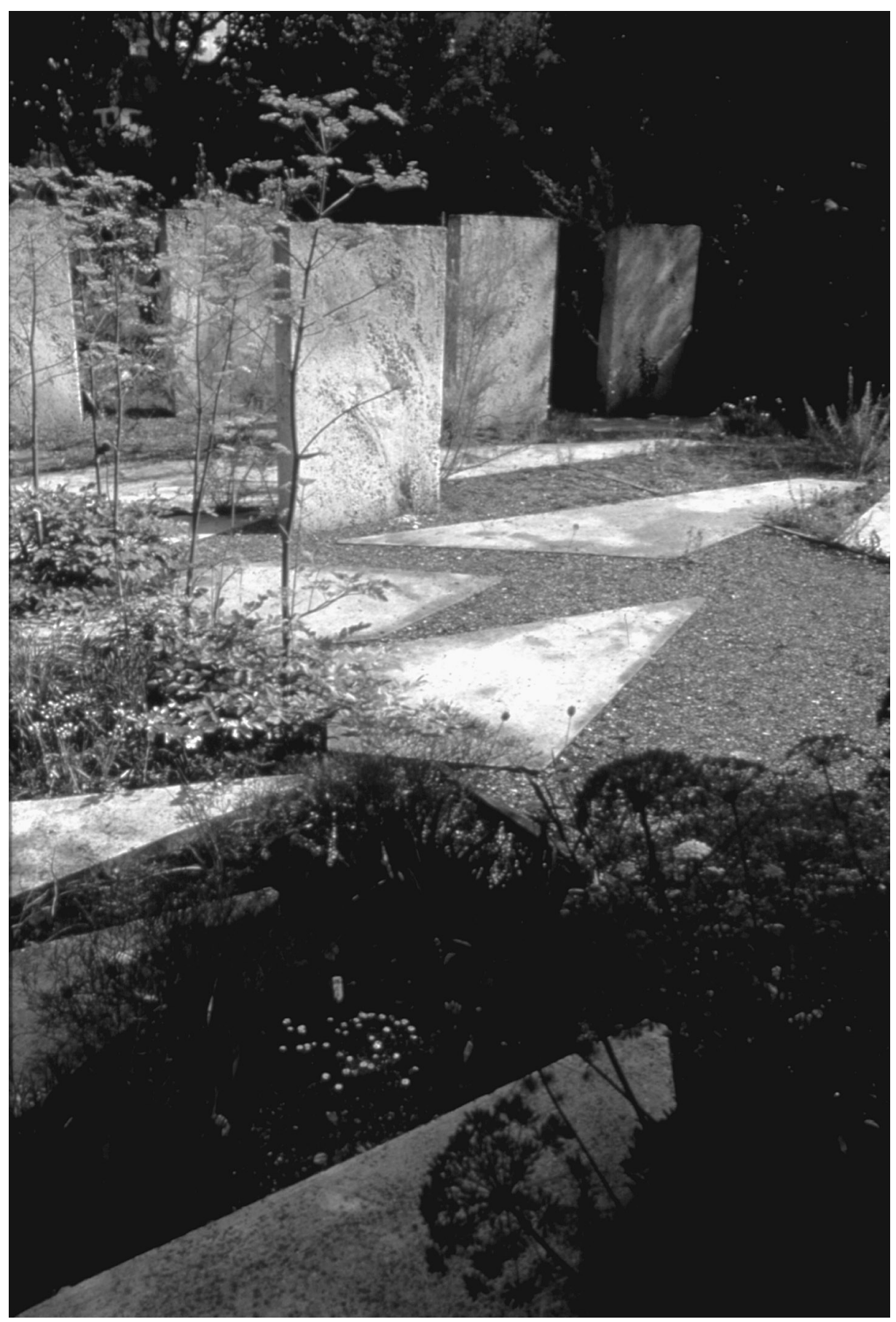

Figure 27. Koenig-Urmi garden, Maur, Switzerland, 1996. Dieter Kienast.Rear garden divided into four soil zones, overlaid with concrete pads. Photograph by Marc Treib. 


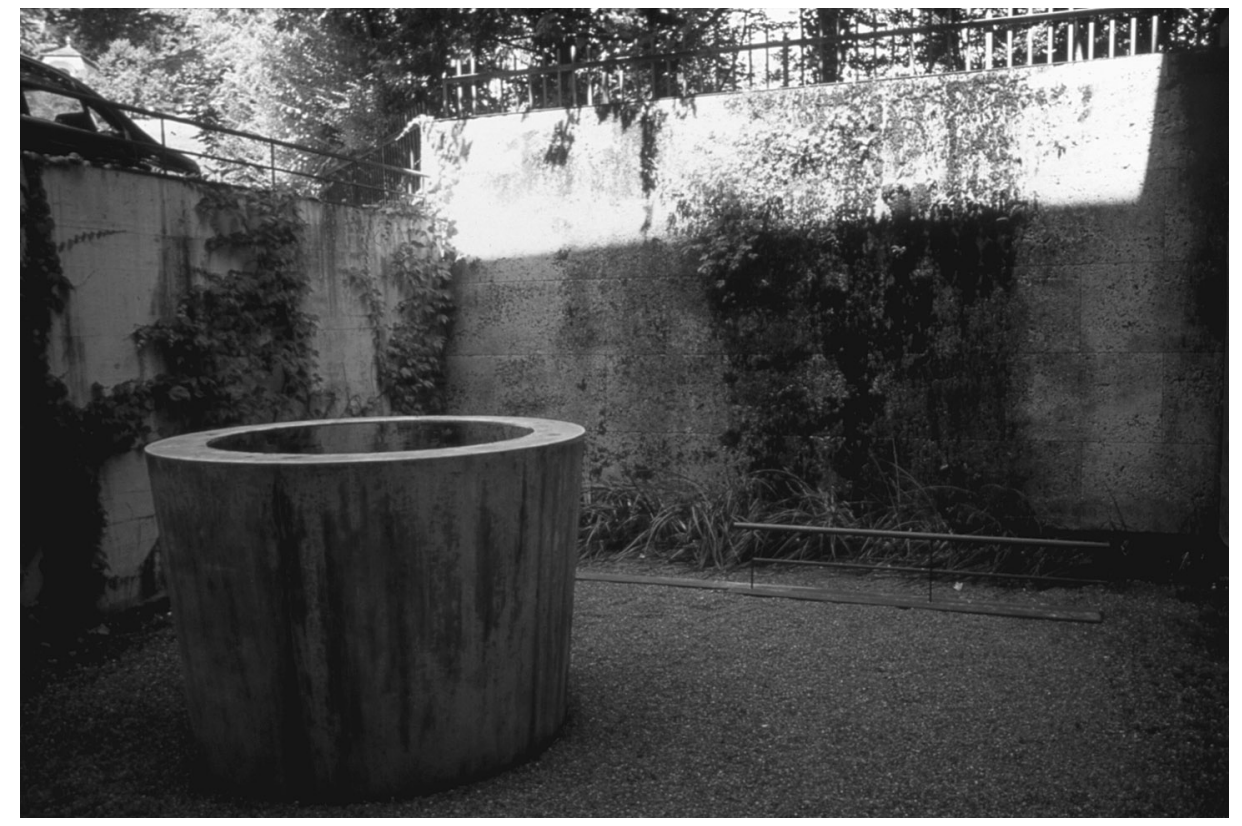

Figure 28. Courtyard, Basler + Partner, Zurich, Switzerland, c.1996. Photograph by Marc Treib.

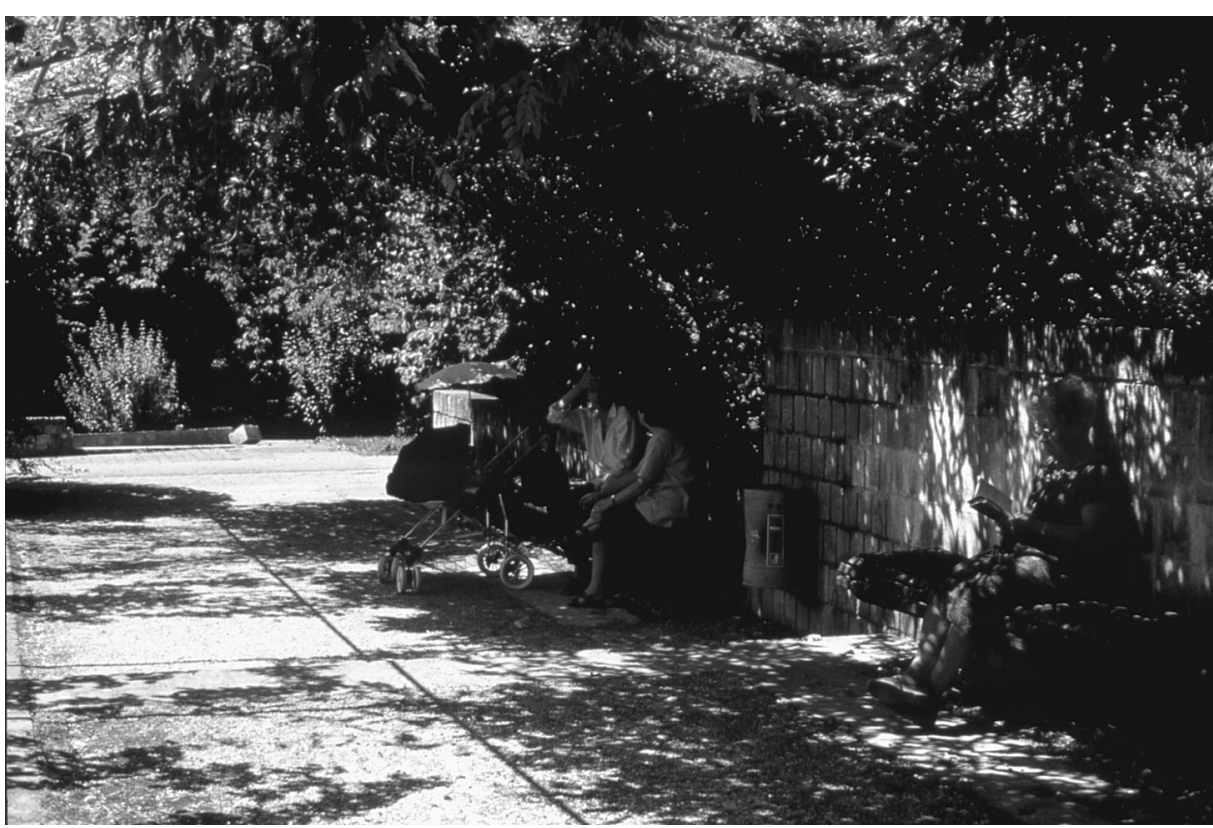

Figure 29. Parc de Lancy, Geneva, Switzerland. 1988. Georges Descombes. General view. Photograph by Marc Treib.

tinct voices. A terrace provided a surface for entertaining or individual retreat; and as a social gesture to the community, the garden jumped the rammed earthen wall to offer its pleasures to passersby.

A cognizance of horticulture and soils was the basis of the design, even the owners didn't know for sure. Thus, underlying the jagged patterning that seems so willful is substantial knowledge and structuring.

Kienast also experimented with the accumulation of mosses on porous lava stone in a manner that might have shamed the entropic yearnings of Robert Smithson. One portion of the Swiss Re project was a wall built of this tufa in which is embedded a series of misters that dampen the surface, and encourage the growth of moss (and one might suspect, mold). Perhaps the pumping system required to maintain the necessary humidity undermines the purity of the idea-for example, would the terrace garner even more respect if the run-off had been used for just this purpose? In fact, Kienast employed just this strategy in a small courtyard for an architectural and engineering firm, Ernst Basler + Partner. Set almost a story below ground, adjacent to six-story office and apartment buildings, this tiny courtyard for Basler + Partner receives almost no direct sunlight (Figure 28). Here the tufa forms a retaining wall infiltrated by ground seepage. Over time the moss reflects the passage of years, the roughness of its wall texture set against the purity and timelessness of the cylindrical water basin fed by piped water runoff.

Planners and designers who stress ecological factors as the sole basis of landscape architecture have often disregarded the idea of landscape architecture as form, space, and cultural practice. Those who favor social use have often rejected landscape design as an art. And those who have designed from aesthetic concerns alone, have often produced landscapes of stillborn human involvement or neglectful of basic site conditions. In contrast, these projects by Dieter Kienast and Hargreaves Associates propose a potent model for park design, gardens, and more broadly landscape architecture; one based perhaps more squarely on episodic planning-if one looks to the ideas rather than the particular forms, and time rather than a single moment. selves did the rest. The garden today has somewhere around 650 species-

\section{Social and Historical Understanding}

Social understanding underpins almost all of the landscape 
designs of Georges Descombes: where to place a bench; how the figure moves; what is the history of the site; how culture enters the discussion. In this context, Descombes's Parc de Lancy in Geneva, Switzerland and the commemorative Voie Suisse on Lake Brunner serve as representative examples.

The Parc de Lancy, which was constructed between 1988 and 1990, lies on the outskirts of Geneva, amidst housing tracts of relatively high density. The first phase of the design addressed a parcel of land assembled from the sites of three suburban villas from the early part of this century. ${ }^{29}$ The terrain slopes steeply from the road toward a shallow ravine; at the lower level vegetation accumulates in a greater presence, and creates a strong contrast Fith the open spaces of the upper zone near the road.

홍 For Descombes, the first act of Gesign was a careful reading of this gapidly-becoming-urban site. Considerations included the contour of the and and its vegetation, physical surroundings such as the neighboring hlousing and shops, and of course Eatterns of pedestrian and vehicular cịculation (Figure 29). To these con-

o

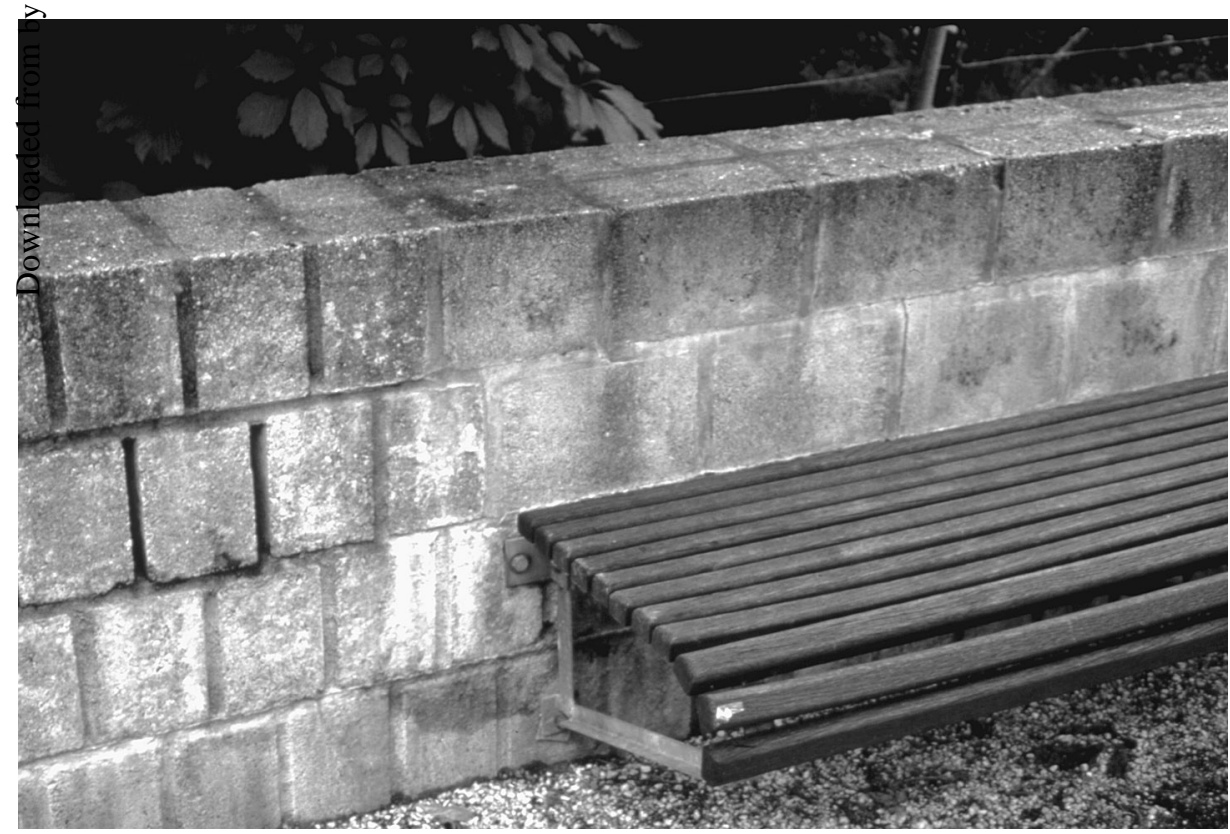

Figure 31. Parc de Lancy, Geneva, Switzerland. 1988. Georges Descombes. Simple wood seat affixed to concrete block wall. Photograph by Marc Treib. Photograph by Georges Descombes. siderations a deeper reading of the park as a place and an institution was added, attempting to understand not only the superficial aspects of the program-rest, relaxation, play,

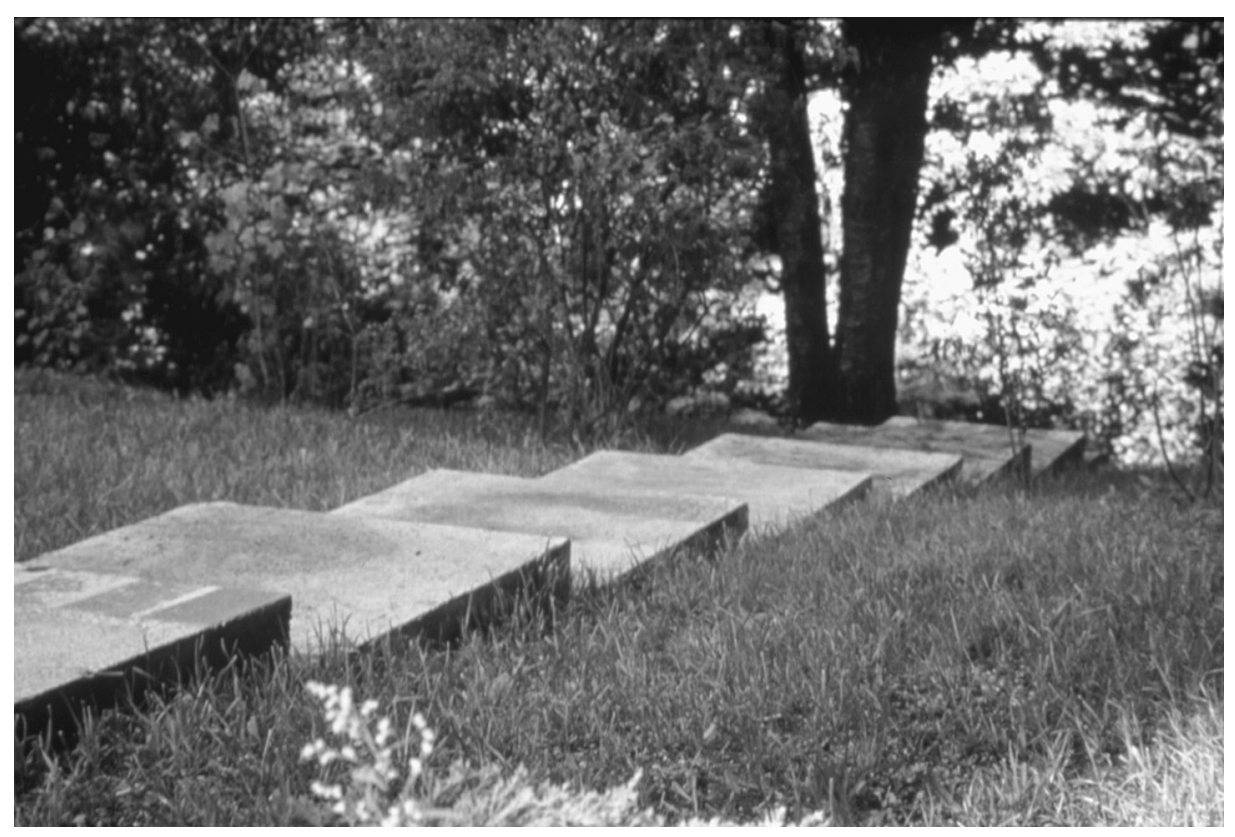

Figure 30. Parc de Lancy, Geneva, Switzerland. 1988. Georges Descombes. Stairs descending the slope towards the stream trace the historic division of villa sites.

social interaction, contact with the outdoors-but also less obvious ideas about society, behavior and the history of the site.

The primary strength of Georges Descombes's work is not rooted in its formal appeal-which, one should note, is considerablebut in its integration of history and behavior into landscape design and architecture. The invisible, intangible aspects of the design do not capture the eye of the camera and yet are deeply felt on site. The limits of the original villa sites, for example, are traced in the pathways and steps that join the upper and lower portions of the land (Figure 30). Understanding the fatigue that accompanies climbing, and in some cases descent, Descombes placed benches and seats where they are logically needed-often superimposed upon retaining walls or walls that double as screens against the wind (Figure 31). He also investigated, at a level beyond the norm, aspects of children's play. The park's central sandbox, for example, is less a tract of undifferentiated play space than a projection of adult politics onto childhood. In con- 


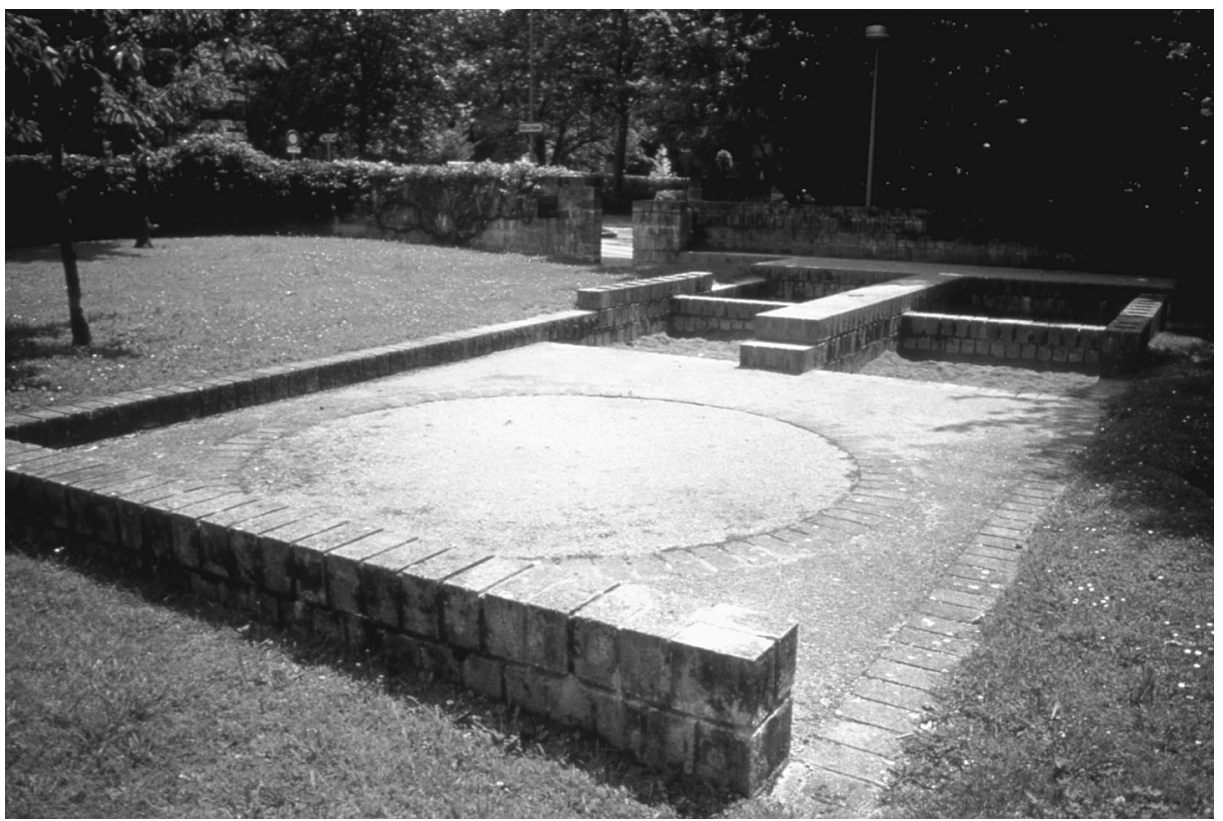

Figure 32. Parc de Lancy, Geneva, Switzerland. 1988. Georges Descombes.

Sandbox divided in four zones with common area. Photograph by Marc Treib.

sultation with a child psychologistand from his own informal observations-Descombes determined that if the sand box area is made as only a single zone, disputes over territory will probably result. Instead, he divided the play space into several defined zones, each identifiable as distinct (Figures 32 and 33)..$^{30}$ These zones psychologically join into one unit, however, as does the house in the neighborhood or the neighborhood into the city. The political lessons for the developing child, though unstressed, seem obvious.

The design of the park developed over time, as the success of the early phases became obvious and the population density grew. While examining the parts of the project in depth is beyond the scope of this essay, one of the park's principal architectural elements may serve as representative. In a subsequent phase of the park's design, a major parcel of land was added on the opposite side of the main road, creating problems of linking the land and people on either side. One could have a traffic light, although this was impractical; neither did a pedestrian overpass seem to be the appropriate solution. In their place, Descombes proposed a tunnel (Figure 34).

Tunnels can be exciting places for children and even adults, but they can also be frightening spaces, whose terrifying darkness is compounded by the sudden shift away from the comforting brilliance of daylight into a dismal zone of insecurity. Descombes translated the tunnel into a site of magic, choreographing light levels and modulating the passage from woods to metal tube as a passage from open nature to confined architecture. The bridge structure extends the tunnel into the land at either terminus, rendering a negative space into a positive one. The landscape architect collaborated with the city road department, and suggested dividing the traffic lanes above the tunnel, allowing a broad median between the two directions of traffic. Here a vertical shaft brings light into the heart of the tunnel; just where it was needed most (Figure 35).

As in the big ideas, so in the details. Common materials comprise the basic palette: concrete block left unstuccoed; elements of vernacular greenhouse systems; the metal tubing of drainage culverts. But these are given heightened design attention, elevating the everyday into the special, much as simple bamboo and clay became prized aesthetic objects through the sophisticated transfor-

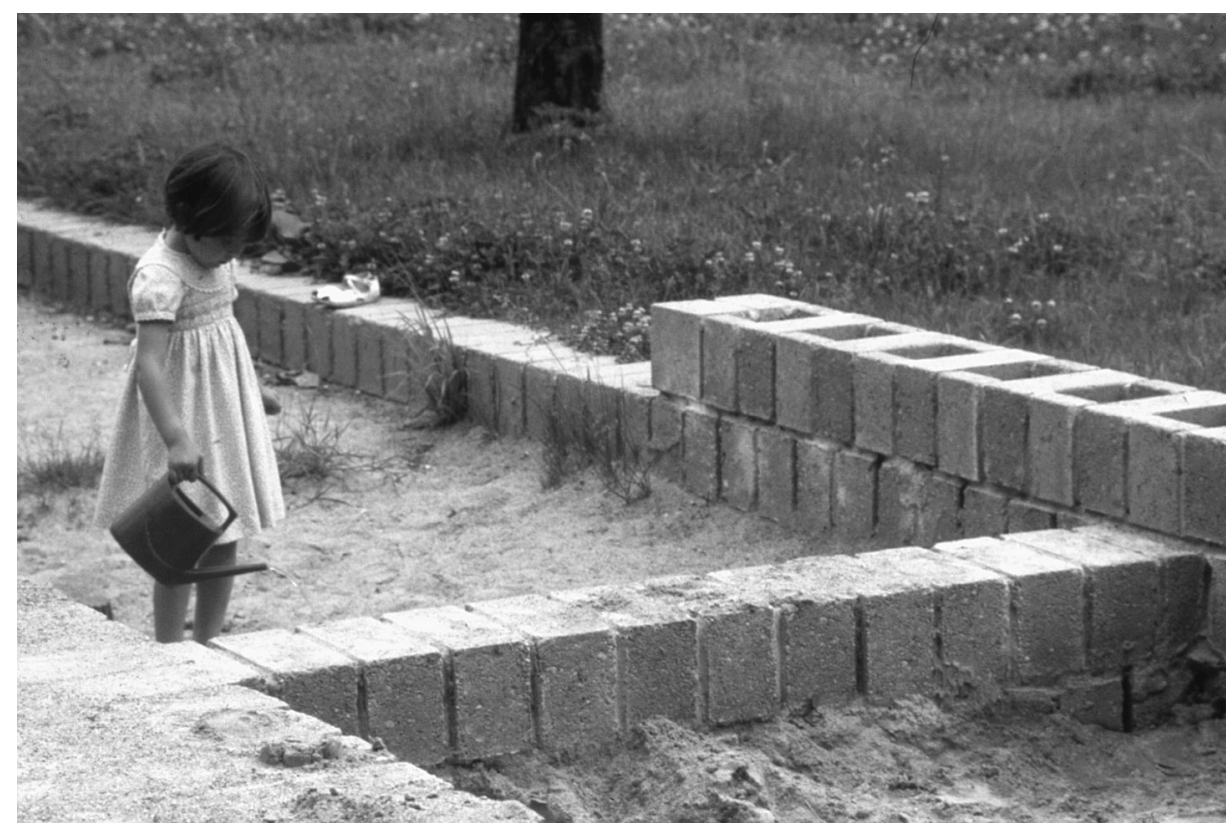

Figure 33. Parc de Lancy, Geneva, Switzerland. 1988. Georges Descombes. Child at play in the sandbox area. Photograph by Georges Descombes. 
mations associated with the tea ceremony in sixteenth-century Japan. ${ }^{31} \mathrm{It}$ is not only in his detailing, but also in his sense of detail, that Georges Descombes is such an unusual designer. Like Carlo Scarpa, he understands that a simple mosaic tile placed in just the right position will reflect light or give color and animate an inanimate surface.(Figure 36). ${ }^{32}$

In many ways, the design for the Voie Suisse on Lake Brunnen follows in the path of the Parc de Lancy. ${ }^{33}$ But in other respects it is a

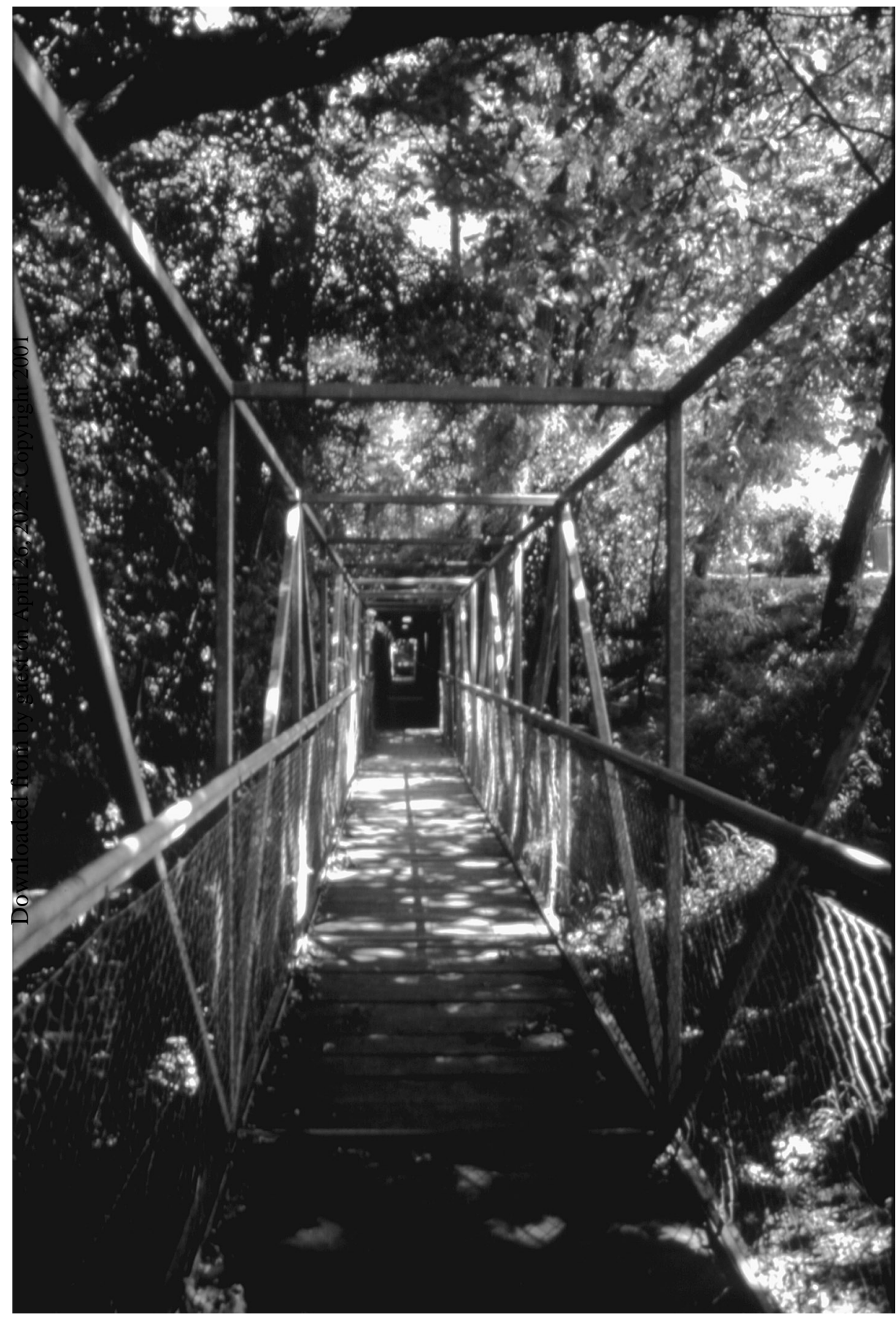

Figure 34. Parc de Lancy, Geneva, Switzerland. 1988. Georges Descombes.

Tunnel with bridge used as a transition to the park. Photograph by Marc Treib. completely independent project that instigated its own way of thinking and its own formal manner. As part of a commemoration of the 800th anniversary of the Swiss Confederation, the various cantons proposed a series of memorials and monuments. Quite typically, Descombes eschewed the monument in favor of a less obtrusive presence; instead of a singular marker, he would propose a landscape two kilometers in length that would underscore the idea of commemoration by absorbing it into that which could only be Swiss: the Swiss landscape itself. The principal design idea, Descombes once said, was to use a broom. ${ }^{34}$ The design of the walk would be less a totally new creation than a revelation of that which once had been in this case an early nineteenth-century Napoleonic road long derelict and almost invisible.

The strategy would be more about replacement and emplacement than about displacement. Using the "broom," the design team swept away accumulations of vegetation and earth. Where the road needed to be reestablished, small concrete blocks provided support and marked the edge. Where surface drainage threatened erosion, open tracks of stainless steel accommodated the safe passage of water (Figure 37 , see contents page). Where railings did not meet contemporary safety standards - in an existing overlook terrace, for example-new structures overlaid the old (Figure 38). Where the terrain was too steep, or where revised pathways created new intersections, the land was stepped simply and functionally to allow for the transition.

The design team included the artists Richard Long and Carmen Perrin. While Long's piece included a letterpress print based on the features of the surrounding landscape, Perrin's contribution was her own particular use of the broom. The site is dotted with erratic boulders; that is, large stones carried by the glaciers far beyond their normal point of de- 
posit. Where most of the local stone is dark gray or black, the erratic boulders are white-their reflective properties kept them relatively cool and underwrote their longer journeys. For Perrin, nothing more was needed than to wash the rocks free of their deposits of moss and dirt (Figure 39). Recast as punctuation marks and sculptural objects within the landscape, the boulders achieved a heightened presence, but they remained an integral fragment of the landscape nonetheless.

One could discuss the formal brilliance and elegance of all the parts of this design in great detail, but more significant is Descombes's derivation of ideas from the history and form of the site, a poignant model of what the artist Robert Irwin called "site conditioned." ${ }_{55} \mathrm{By}$ this, Irwin implied a sculptural art that could come only from that place at that time under those conditions. There is no way that one can grasp the essence of the Voie Suisse or Lancy landscapes in photographs because it is not concerned with formal structuring. Unfortunately, words may increase our understanding but not necessarily our experience on site, which is broadly cinematic. Because the work extends for a mile and a half, the visitor encounters the landscape in a linear manner. But this is not the linearity of a single ribbon or a single wire filament. A better analogy would be a frayed cable, with twisted multiple strands whose breaks cause impulses or stoppages along the way. At certain points the way is physically challenging, causing the visitor to heed the act of walking. In other places, where the slope flattens or a gap in the forest reveals a vista, the event rather than the path controls perception. Underlying the entirety of this episodic path and movement is the micro-scale of earth, flowers, and shrubs. (A part of the project involved selective reseeding with native wild flowers).

Descombes's regard for behavior, site, history, and structure also informed his design for the 1998 Bijlmeer Memorial outside Amsterdam (Figure 40). Only the more dominant formal elements of the design - the canal, the fountain, and the long concrete retaining walls that double as benches and tablesattract the viewer in photographs. The sense of longing and absence, however, remain unrecorded. There is no way to transport a landscape by
Georges Descombes to another place because the place itself is its most important element. The landscape architect's project here utilizes the eternalized moment of history to inform the making of physical places.

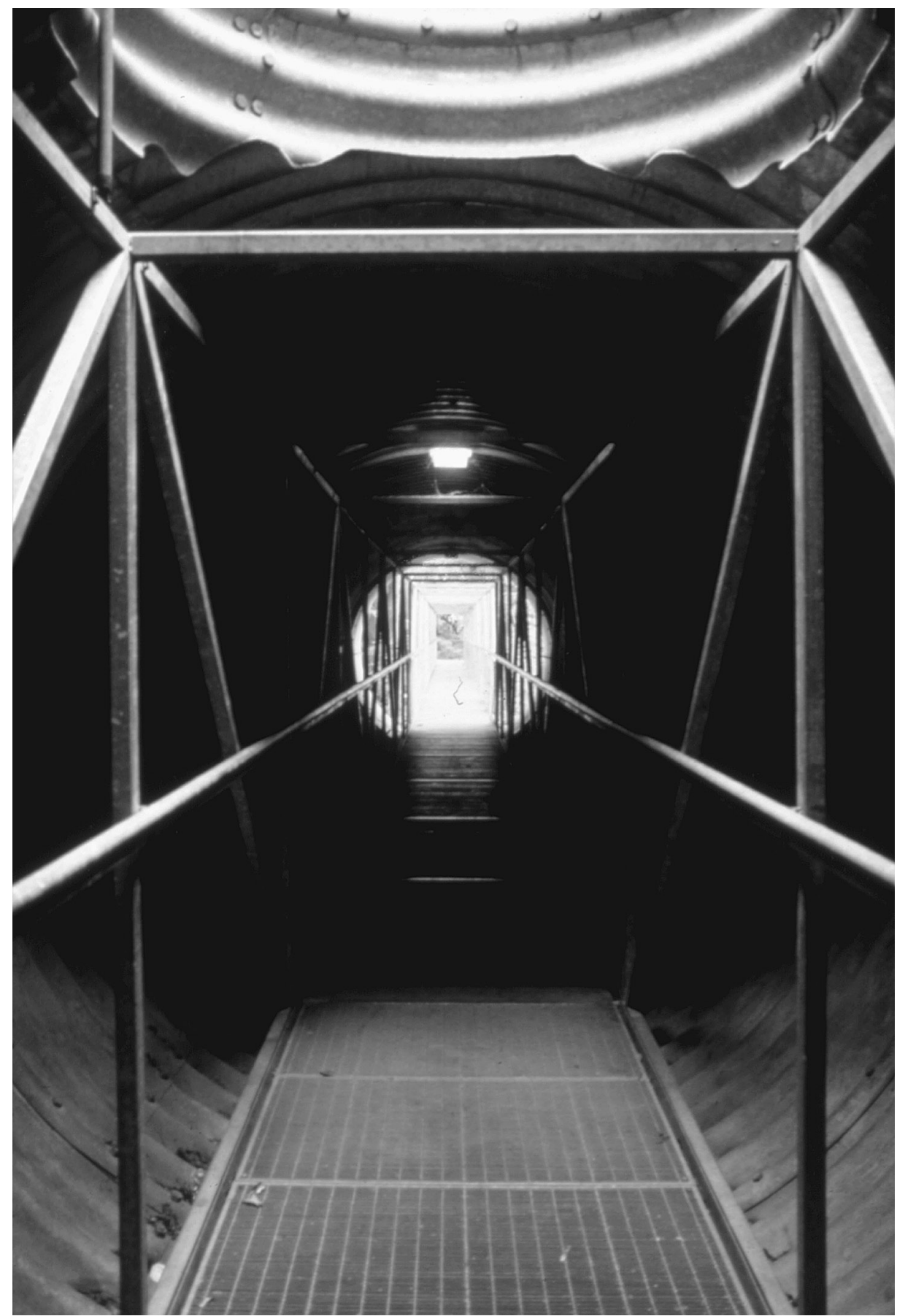

Figure 35. Parc de Lancy, Geneva, Switzerland. 1988. Georges Descombes. The park uses common materials such as concrete block and metal culvert pipe, here used to form the tunnel connecting two areas of the park. Photograph by Marc Treib. 
The landscape must succeed in the present-social provisions, construction intelligence, aesthetic interestamalgamating the voices of the past with those of the present.

\section{Conclusion}

In this essay, I have tried to establish the possibilities and limits of landscapes that give primacy to the formal conditions of landscape architecture and patterns that the photograph easily comprehends-and that journals quickly publish for visual consumption. Instead, I would propose that we continue to seek a landscape architecture that engages more fully aspects of human and natural presence, as well as human and natural histories, poetically elevating them through formal dexterity. To provide drainage or seating is only 严e first response; then one can make That canal or bench beautiful in itself ब्र्मूd, perhaps more importantly, an integral contributor, if not instigator, For the greater scheme. As Edward Wheston once said: "Photograph a Ehing not for what it is, but for what êd.

त Of course, all of this must seem rery simple and very preachy, as if this thesis were the first lesson in any land-

产

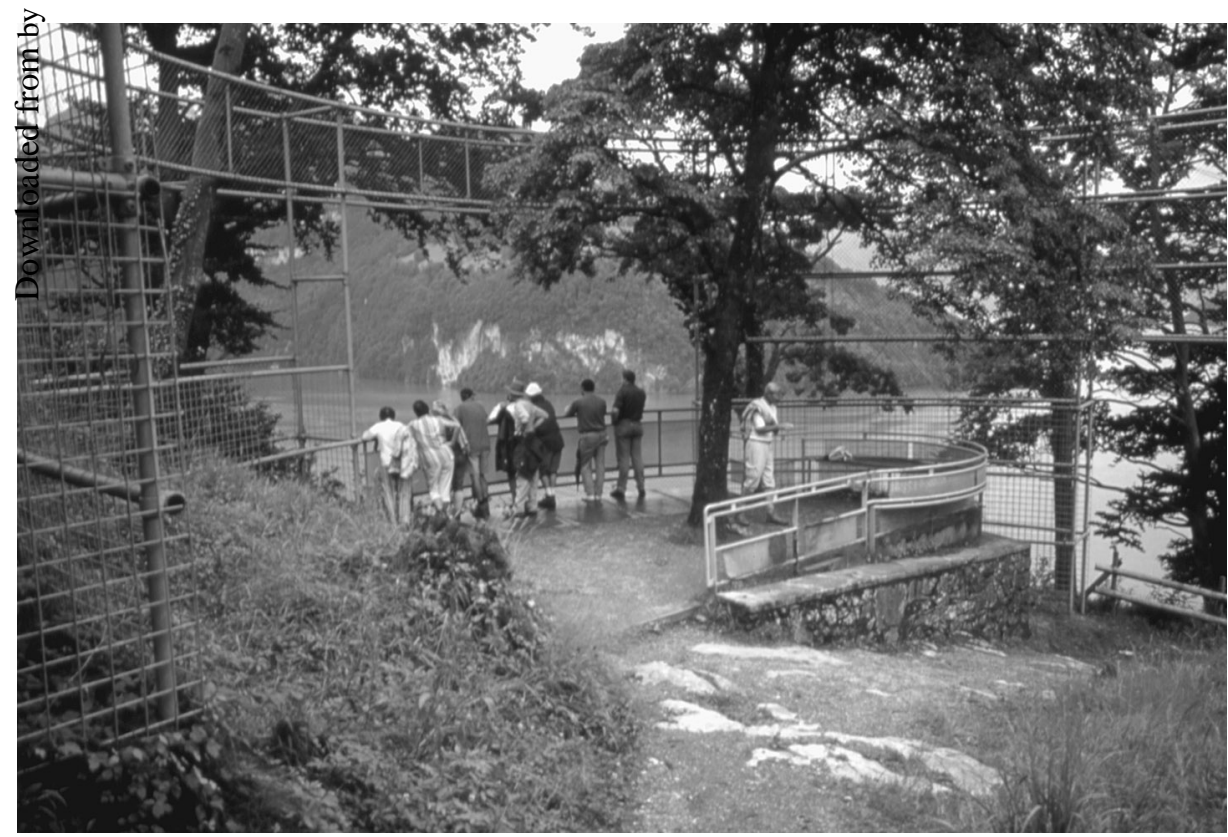

Figure 38. Voie Suisse, Lake Brunnen, Switzerland, 1990. Georges Descombes. The new metal mesh belvedere overlays an older overlook terrace. Photograph by Marc Treib. Marc Treib. scape architecture curriculum. Perhaps it is; I believe it should be. But I also believe that the lure of the photograph and the attraction of the media today have reduced our interest in these very basic concerns, which is un-

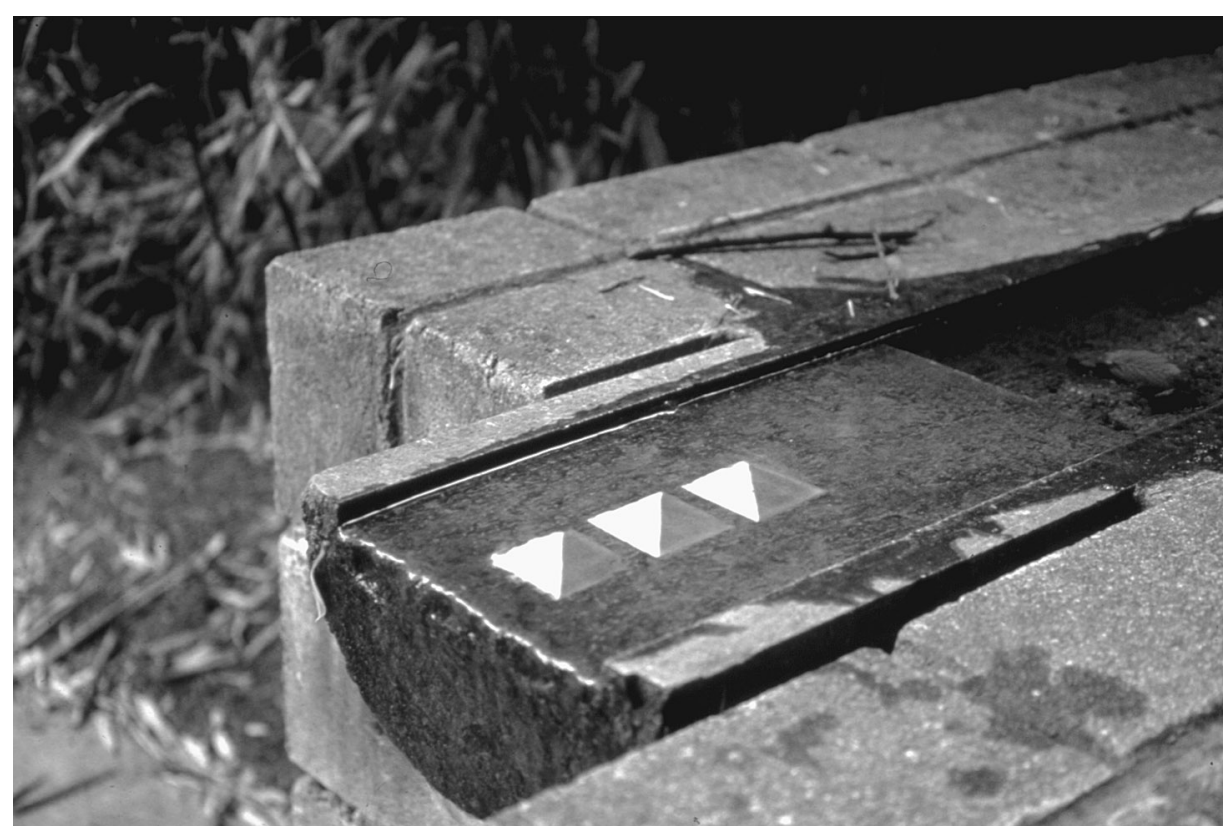

Figure 36. Parc de Lancy, Geneva, Switzerland. 1988. Georges Descombes. Insertions of mosaic tile provide color and sparkle in reflected light in shaded areas. Photograph by

fortunate. Given the continued evolution of the landscape and its cultural matrix, we should not stop in our attempts to understand their changing content, or in our search for new manners in which to make them.
Notes

An earlier version of this essay was presented at the 1999 meeting of the International Confederation of Landscape Architects, held in Copenhagen, Denmark.

Trespassing onto such slippery philosophical slopes as those encountered here can only lead to trouble, compounded by the absence of any fixed answers to the questions raised. But as the Zen scholar D.N. Suzuki once said after a particularly animated class discussion: "That's what I like about philosophy: no one wins, no one loses." For intelligently challenging an earlier draft and helping guide my rethinking, revising, and expansion of the essay I wish to thank the journal's three anonymous readers, and Editor Kenneth Helphand.

1. I have examined this issue in an earlier article in this journal. Marc Treib, "Must Landscapes Mean? Approaches to Significance in Recent Landscape Architecture," Landscape Journal, Spring 1995, pp.46-62.

2. A review essay of books concerned with landscape photography centers on this issue: Marc Treib, "Frame, Moment, and Sequence, 


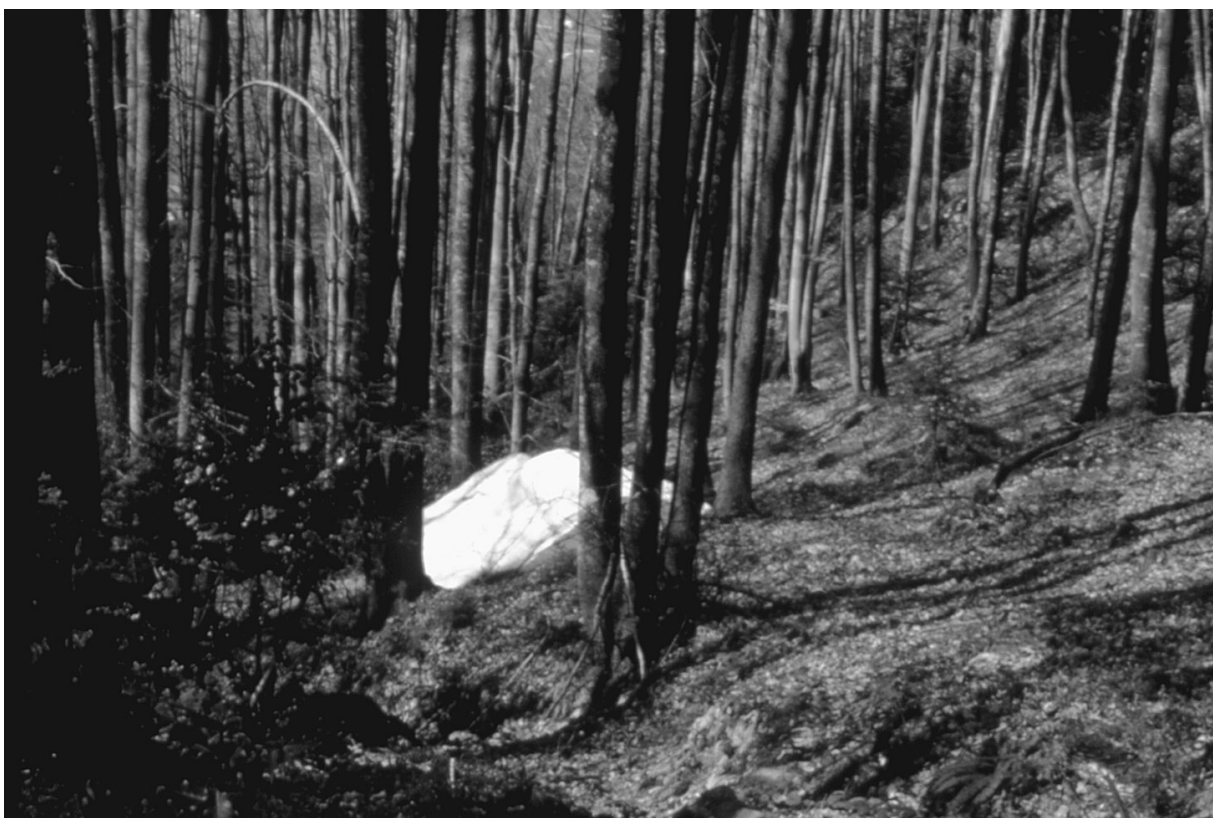

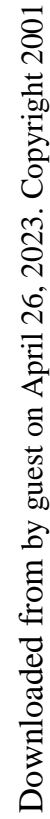

Figure 39. Voie Suisse, Lake Brunnen, Switzerland, 1990. Carmen Perrin. The artist's team scrubbed the dirt and moss from erratic boulders, rendering them white sculptural forms. Photograph by Georges Descombes.

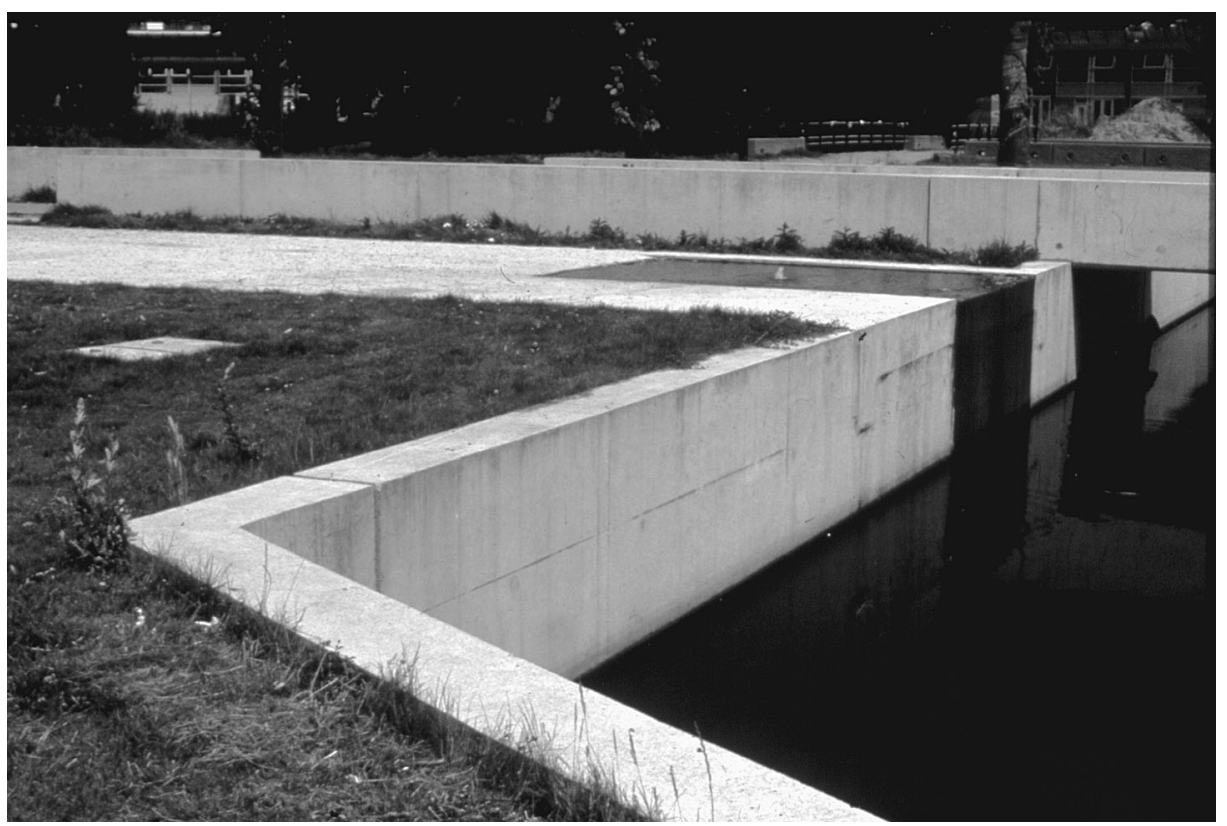

Figure 40. Bijlmeer Monument. Amsterdam, The Netherlands, 1998.

Georges Descombes. The configuration of the project derived from the footprints of the housing blocks destroyed in the crash. A single fountain feeds a sheet of water that quietly stains the concrete as it falls into the canal. Photograph by Marc Treib.
Journal of Garden History, Summer 1995, pp.126-134.

3. Frederick Law Olmsted and Calvert Vaux, relatively early in the history of photography, used the medium in presenting their

"Greensward" design for New York's Central Park. The before (photograph)-and-after (sketch) aspect of these presentations probably derives from the "slides" prepared by Humphry Repton for his varied landscapes. See Elizabeth Barlow, Frederick Law Olmsted's New York, New York: Praeger, 1972, in particular pp.72-73.

4. The English language is unkind here, providing one word to cover at least two greatly differing applications. The word "formal" may address "of or pertaining to form," the adjective drawn from the noun. On the other hand, it may be used as the antonym of "informal," which in landscape terms translates, for example, as gardens planned according to geometry as opposed to those based on nature. In the past and, I fear, also in the current essay, I have found no way to graciously resolve the issue nor to find other words that convey nearly the same meaning. See Marc Treib, "Formal Problems," Studies in the History of Gardens and the Designed Landscape, April-June 1998, pp.71-92.

5. See Clement Greenberg, "Modern Painting," (1960), reprinted in Charles Harrison and Paul Wood, editors, Art in Theory, 19001990, Oxford: Blackwell, 1992, pp.754-760. 6 . The merits of these distinctions have been dismissed by some critics, however. See John Dixon Hunt, Greater Perfections, Philadelphia: University of Pennsylvania Press, 2000, especially pp.170-75. Here, with good reason, the author takes issue with the recurring dichotomy in general, and my essay, "Formal Problems" (cited above) in particular.

7. One could easily imagine, however, those deprived of vision more heavily favoring the perception of the landscape by other senses such as touch, sound, or fragrance.

8. Dave Hickey, "Bridget Riley for Americans, in Bridget Riley: Paintings 1982-2000 and Early Works on Paper, New York: Pace Wildenstein, 2000, pp.8-9.

9. John Brinckerhoff Jackson, "The Word Itself," in Discovering the Vernacular landscape, New Haven: Yale University Press, 1984, p.5. 10. See Marc Treib, "Aspects of Regionality and the Modern (ist) California Garden," in Therese O'Malley and Marc Treib, eds., Regional Garden Design in the United States, Washington, DC: Dumbarton Oaks, 1995, pp.5-42. 11. Yi-Fu Tuan, Topophilia: A Study of Environmental Perception, Attitudes and Values, Englewood Cliffs, NJ: Prentice-Hall, 1974.

12. The annual awards program of the American Society of Landscape Architects also cites projects in research, planning, and communication. In this paper, I remain directed to answering questions of landscape design that are or could be realized rather than studies about landscapes.

13. "Form in art is as varied as idea itself. It is the visible shape of all man's growth; it is the living pictures of his tribe at its most primitive, and of his civilization at its most sophisticated state. Form is the many faces of the legendbardic, epic, sculptural, musical, pictorial, 
architectural; it is the infinite images of religion; it is the expression and the remnant of self. Form is the very shape of content." Ben Shahn, The Shape of Content, New York: Vintage Books, 1957, p.62.

14. See Linda Jewell, editor, Peter Walker: Experiments in Gesture, Seriality and Flatness, New York: Rizzoli, 1990; Peter Walker, "The Practice of Landscape Architecture in the Postwar United States, in Marc Treib, ed. Modern Landscape Architecture: A Critical Review, Cambridge, Mass: MIT Press, 1993, pp.250-59; and Marc

Treib, "Motifs, trames et structures" (The Place of Pattern)," Pages Paysages \#4, 1992-93, pp.128-133.

15. The extreme example of this phenomenon is the work of Andy Goldsworthy, whose sculpture is often more powerful in photographs than in actuality. The play between the installation and the defining rectangle of the photographic frame heightens the presence of the work and removes it from its greater contextof which, often, it is only a very small part. Rather than reading a spiral of colored leaves against the irregular patterns of natural elements, for example, we read it against the photographic frame infilled with the irregular patErning of nature. See Andy Goldsworthy, Aand to Earth: Andy Goldsworthy Sculpture E976-90, New York: Abrams, 1990.

Dichard Long's documentation of his lks differs in that the photograph is a จुnemonic device for the artist and a narrative device for the viewer. The photograph recalls the event as marked by Long's construction rather than as acting as part of the work itself. see R.H. Fuchs, Richard Long, New York: Guggenheim Museum, 1986; and Richard R. ittell and Dana Friis-Hansen, Richard Long: Gircles, Cycles, Mud, Stones, Houston: Contemporary Arts Museum, 1996.

$\forall$. For a discussion of the ideas behind the Mrk and its design process, see Alistair T. McIntosh, "Burnett Park," in Jewell, Peter Elalker, pp.30-37.

. This project is presented in Dan Kiley and Jane Amidon, Dan Kiley: Complete Works, \$oston: Bulfinch, 1999, pp.106-112; and Dan
Kiley: In Step with Nature; Landscape Design II, Process Architecture 108, 1993, pp.46-54.

18. Tom Maver in conversation with the author, Solana, November 1996.

19. While this essay was in press, Kenneth Helphand informed me that the proscription of tree planting over garbage fills no longer directs current practice. I thank him for bringing this to my attention. At the time that Byxbee was designed, however, these restrictions were in place.

20. I would imagine that few clients would be thrilled by the idea that their garden will erode over time, or that distinctions of bed and lawn might disappear with the spread of weeds or native grasses. The distribution of grasses and wildflowers through reseeding, or the growth of volunteer trees over time, might constitute beneficial examples of applied entropic order, however. The most important of Smithson's essays to focus on this subject is "A Tour of the Monuments of Passaic, New Jersey," (originally published in Artforum December, 1967), in Nancy Holt, The Writings of Robert Smithson, New York, New York University Press, 1979, pp.52-57. As early as 1971, art historian and psychologist Rudolph Arnheim had published Entropy and Art: An Essay on Order and Disorder, Berkeley: University of California Press, examining this natural drift in relation to art production.

21. These forms, in fact, have become a signature element in the Hargreaves Associates landscape, appearing in all the waterfront designs, but are less apparent here-at least so far-due to thick natural vegetation. Plantations of palms, poplars and conifers reinforce the patterns set at ground level. While some areas have already been completed, work will continue for half a decade.

22. The site was first slated for redevelopment in the mid-1980s.

23. There will be some few structures for dining or recreation, but the hotels and housing of the original proposal will have to address the river from beyond the limits of the park. 24. As of January 2001.

25. George Hargreaves, in conversation with the author, Cambridge, Massachusetts, October 1997.

26. Gilles Clément, Le Jardin en mouvement: de la vallée au Parc André Citroën, Paris: Sens \& Tonka, 1994

27. Dieter Kienast, Gärten Gardens, Basel: Birkhäuser Verlag, 1997.

28. Dieter Kienast, Gärten, p.168.

29. For an overview of this projects see Giordano Tironi, editor, Il Territorio Transitivo / Shifting Sites, Rome: Gangemi editore, 1998. 30. What should happen if there are more than four play groups, however, is open to question.

31. This elevation of common objects to the status of high art depended on erudition in taste and painstaking selection or reworking. As the museum today recontextualizes ethnographic or artistic production, the teahouse removed the everyday object from its mundane context, elevating its aesthetic status by an appreciation of its simple values. In actual practice, the tea masters more commonly developed their own arts with a nod in the direction of the everyday rather than extensively using truly common wares.

32. In his use of the judiciously placed reflective metallic tiles, Descombes recalls elements of the 1969-78 Brion Cemetery San Vito d'Altivole, and the 1973 garden for Palazzo Querini-Stampaglia in Venice, both designed by Carlo Scarpa.

33. A book documents the process and the elements of the project: Voie Suisse, l'itinéraire genevois: De Morschach à Brunnen, Fribourg: Canton de Genève, 1991. Descombes considers the book a part of the project, the landscape of which was understood to be ephemeral.

34. Georges Descombes in conversation with author, July 1999, Geneva.

35. Robert Irwin, Being and Circumstance: Notes toward Conditional Art, Larkspur Landing, California: Lapis Press, 1985, pp.26-27.

36 . I have not been able to locate the exact source of this quote, although I suspect it comes from Nancy Newhall, editor, The Daybooks of Edward Weston, New York: Horizon Press, 1966. 